\title{
Dip angles of active faults from the surface to the seismogenic zone inferred from a 2D numerical analysis of visco-elasto-plastic models: a case study for the Osaka Plain
}

\author{
Hayami Nishiwaki ${ }^{1 *}$,Takamoto Okudaira ${ }^{1 *} \mathbb{0}$, Kazuhiko Ishii ${ }^{2}$ and Muneki Mitamura ${ }^{1}$
}

\begin{abstract}
The geometries (i.e., dip angles) of active faults from the surface to the seismogenic zone are the most important factors used to evaluate earthquake ground motion, which is crucial for seismic hazard assessments in urban areas. In Osaka, a metropolitan city in Japan, there are several active faults (e.g., the Uemachi and Ikoma faults), which are inferred from the topography, the attitude of active faults in surface trenches, the seismic reflection profile at shallow depths (less than $2 \mathrm{~km}$ ), and the three-dimensional distribution of the Quaternary sedimentary layers. The Uemachi and Ikoma faults are N-S-striking fault systems with total lengths of $42 \mathrm{~km}$ and $38 \mathrm{~km}$, respectively, with the former being located $\sim 12 \mathrm{~km}$ west of the latter; however, the geometries of each of the active faults within the seismogenic zone are not clear. In this study, to examine the geometries of the Uemachi and Ikoma faults from the surface to the seismogenic zone, we analyze the development of the geological structures of sedimentary layers based on numerical simulations of a two-dimensional visco-elasto-plastic body under a horizontal compressive stress field, including preexisting high-strained weak zones (i.e., faults) and surface sedimentation processes, and evaluate the relationship between the observed geological structures of the Quaternary sediments (i.e., the Osaka Group) in the Osaka Plain and the model results. As a result, we propose geometries of the Uemachi and Ikoma faults from the surface to the seismogenic zone. When the friction coefficient of the faults is $\sim 0.5$, the dip angles of the Uemachi and Ikoma faults near the surface are $\sim 30^{\circ}-40^{\circ}$ and the Uemachi fault has a downward convex curve at the bottom of the seismogenic zone, but does not converge to the Ikoma fault. Based on the analysis in this study, the dip angle of the Uemachi fault zone is estimated to be approximately $30^{\circ}-40^{\circ}$, which is lower than that estimated in the previous studies. If the active fault has a low angle, the width of the fault plane is long, and thus the estimated seismic moment will be large.
\end{abstract}

Keywords: Dip angle, Fault geometry, Visco-elasto-plastic simulation, Uemachi fault zone, Ikoma fault zone, Osaka Group, Osaka Plain, 2018 northern Osaka earthquake, Active fault, Seismogenic zone

\section{Introduction}

The 2018 northern Osaka earthquake occurred on June 18, 2018, and its epicenter was located at the junction of the Arima-Takatsuki fault zone and the Ikoma fault

\footnotetext{
*Correspondence: m19sc019@jr.osaka-cu.ac.jp; oku@sci.osaka-cu.ac.jp

1 Department of Geosciences, Osaka City University, Osaka 558-8585,

Japan

Full list of author information is available at the end of the article
}

zone (Fig. 1a). The focal mechanism solution for this earthquake showed a N-S-striking reverse fault type (Kato and Ueda 2019). If the dip angle of the Uemachi fault zone, which is a reverse fault with a N-S strike and E dip, is approximately $40^{\circ}$, the downward extension of the Uemachi fault zone would nearly coincide with the hypocenter of the earthquake (Fig. 2). However, the relationship between this earthquake and the Uemachi fault zone is still unknown because the attitude (i.e., the 


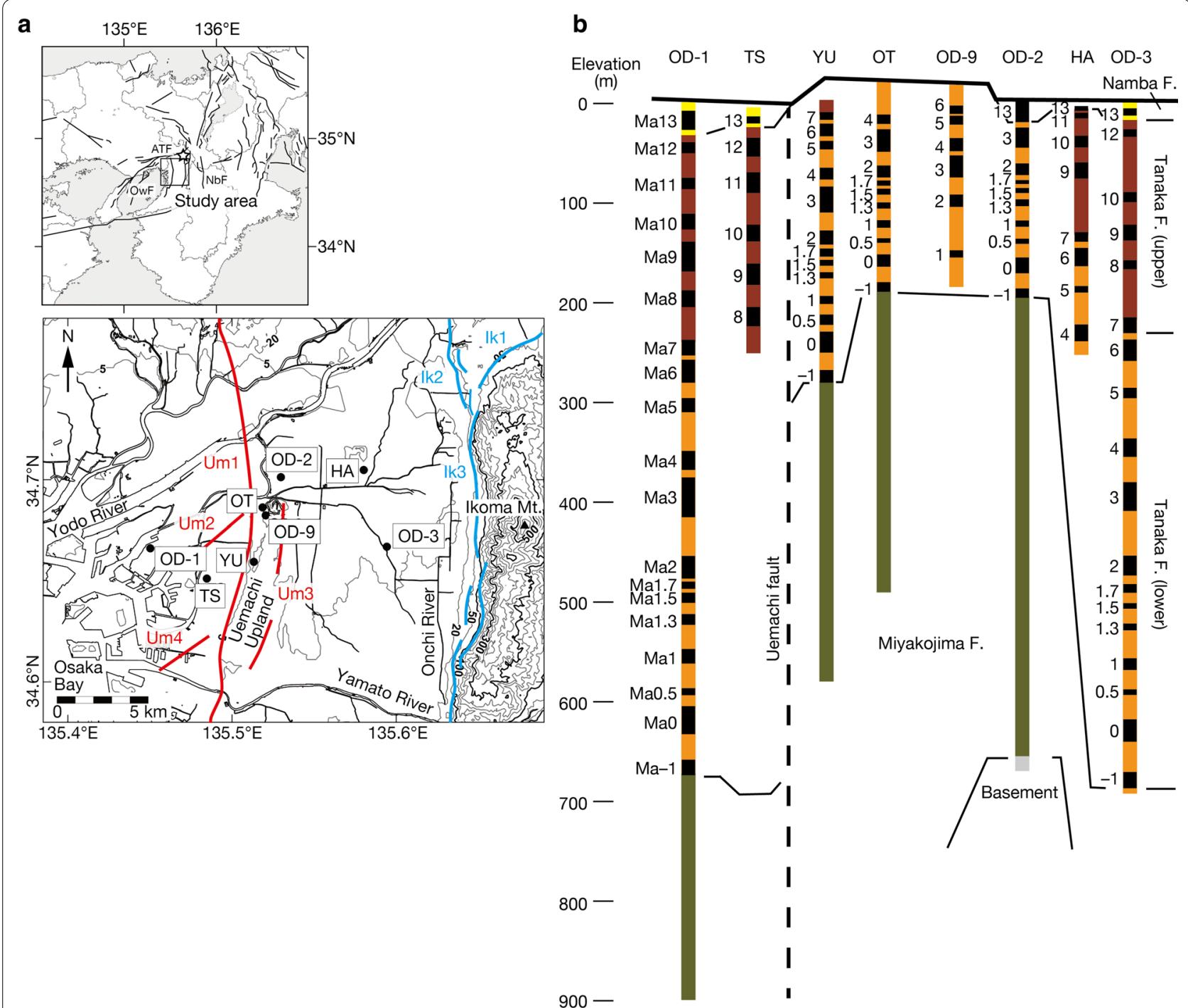

Fig. 1 a Locations of the drilling sites on the Osaka Plain referred to in this study. Faults and flexures of the Uemachi fault zone, as illustrated in red, include the Uemachi fault (Um1), Sakuragawa flexure (Um2), Nagai fault (Um3), and Suminoe flexure (Um4), and those of the Ikoma fault zone, as illustrated in blue, include the Katano fault (Ik1), Hirakata fault (Ik2), and Ikoma fault (Ik3) (Headquarters for Earthquake Research Promotion of MEXT 2001, 2004). The Butsunenji-yama and Taguchi faults, and the Sakamoto, Kumedaike and Konda faults are located to the north and the south of the mapped area, respectively. The inset indicates the location of the study area. Inland active faults in and around the Kinki region (Headquarters for Earthquake Research Promotion of MEXT 2005) are also shown in the inset. ATF, OWF, and NbF represent faults and flexures of the Arima-Takatsuki fault zone, Osaka-wan fault zone, and Nara Basin eastern edge fault zone, respectively. The epicenter of the 2018 northern Osaka earthquake proposed by Kato and Ueda (2019) is indicated by a star. b Columnar sections of the OD-1, TS, YU, OD-9, OT, OD-2, HA, and OD-3 drilling cores (partially modified from Uchiyama et al. 2001). Basement rock, Miyakojima Formation, lower Tanaka Formation, upper Tanaka Formation, Namba Formation, and marine clay layer are illustrated in gray, brownish green, orange, brown, yellow, and black, respectively

strike and dip angle) of the Uemachi fault zone at the depth of the seismogenic zone is poorly understood. Similar to the Uemachi fault zone, the attitude of active faults, including the Ikoma fault zone, in the Osaka Plain within the seismogenic zone (at a depth of $\sim 10-15 \mathrm{~km}$ ) is not clear. The topography, the attitudes of active faults in surface trenches, seismic reflection profiles at shallow depths (less than $2 \mathrm{~km}$ ), and the three-dimensional distribution of the Quaternary strata based on geological drilling columns have been used by the Headquarters for Earthquake Research Promotion of MEXT and the Central Disaster Prevention Council to evaluate the activities of each active fault. The deep underground attitudes of active faults have been estimated by extrapolation of the attitude near the surface (e.g., Headquarters for 


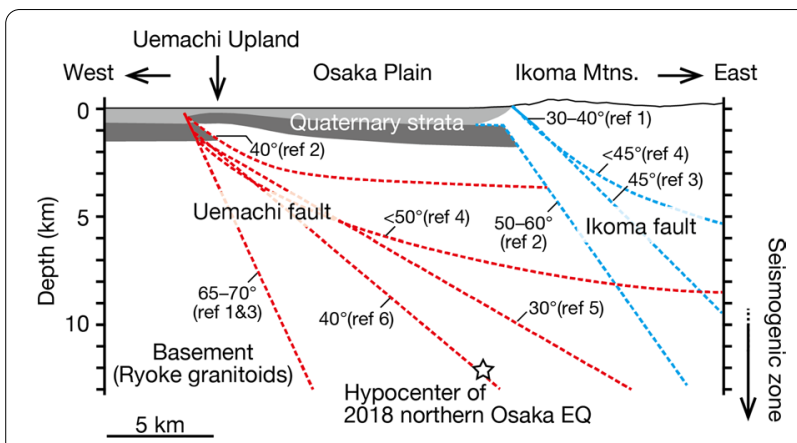

Fig. 2 Summary of the inferred geometries of the Uemachi and Ikoma faults in the Osaka Plain illustrated on a schematic geological cross section (modified partially from Ishiyama 2003). Here, references 1, 2, 3, 4, 5 and 6 correspond to Headquarters for Earthquake Research Promotion of MEXT (2001, 2004), Ishiyama (2003), Director General for Disaster Management (2006), Sato et al. (2009), Iwasaki (2016) and Kato and Ueda (2019), respectively. The hypocenter of the 2018 northern Osaka earthquake (EQ) proposed by Kato and Ueda (2019), located $12 \mathrm{~km}$ beneath the surface position $14 \mathrm{~km}$ east from the Uemachi fault, is indicated by a star

Earthquake Research Promotion of MEXT 2001, 2004; Director General for Disaster Management 2006; Fig. 2).

To mitigate earthquake damage, it is essential to predict ground motion caused by earthquakes that occur on active faults, and the attitude of the source fault in the seismogenic zone is one of the most important factors used to predict the ground motion. If the source fault has a low angle, the width of the fault plane is long, and thus the estimated seismic moment will be large. In the shallow part of the active faults with low dip angles, the fault plane is close to the ground surface and then peak ground acceleration will be higher (e.g., Midorikawa 1993). However, because geological and geophysical observations are restricted to shallow depths, the attitude of the active faults at the depth of the seismogenic zone is not well understood. Therefore, a numerical analysis would be useful to estimate the attitude of the active faults at depth, based on a comparison between the results of numerical analyses and the geological and geophysical observations. In the Osaka Plain, the Kinki region, Japan (Fig. 1), to clarify the distribution of active faults, many geological and geophysical observations have been performed, and then it is a good field for the evaluation of the attitude of the active faults at depth estimated by a comparison between the results of the numerical analysis and the geological and geophysical observations.

To estimate the dip angles of the active faults at depth in the Osaka Plain, simple numerical analyses were performed to determine how the deformation of the strata and the ground surface changes as a result of different fault dip angles; the simulation results can be compared to the distribution of the strata in the Osaka Group and the inclination angle of the axial plane of the subsurface flexure of the Uemachi fault (Ishiyama 2003; Iwasaki 2016; Fig. 2). However, these dip angles were obtained based on a comparison between deformation structure of the pre-deposited strata due to a kinematically imposed movement of the basement along the fault, without considering the sedimentation process and the fault behavior under the assumed stress field, and the geological observations. Furthermore, the rheological properties of the rocks and sediments have not been considered in the previous studies.

In this study, to examine the geometries of the Uemachi and Ikoma faults at the depth of the seismogenic zone, we analyze the development of geological structures in the sedimentary layers based on numerical simulations of a two-dimensional visco-elasto-plastic body under a horizontal compressive stress field, including preexisting high-strained weak zones (i.e., faults) and surface sedimentation processes, and evaluate the relationship between the observed geological structures of the Quaternary sediments (i.e., the Osaka Group) in the Osaka Plain and the model results.

\section{Constraints on the numerical simulation: Quaternary geology in the Osaka Plain}

The Osaka sedimentary basin is an oval topographical depression surrounded by mountains, and the Osaka Bay and the Osaka Plain are located in its western and eastern regions, respectively. The boundary between the Osaka Plain and the surrounding mountains is demarcated to the north by the ENE-WSW-trending ArimaTakatsuki fault zone and to the east by the $\mathrm{N}-\mathrm{S}$-trending Ikoma fault zone. The $\mathrm{N}-\mathrm{S}$-trending Uemachi fault zone is located in the central part of the Osaka Plain (Fig. 1a). Quaternary crustal deformation in and around the Osaka sedimentary basin is referred to as the Rokko movements (Ikebe and Huzita 1966; Huzita 1968, 1990) and results from the subduction of the Pacific Plate and the Philippine Sea Plate at the Japan Trench and at the Nankai Trough, respectively (Huzita 1968; Itoh et al. 2000). Based on a comparison between the present stress conditions, the direction of the horizontal maximum stress $\left(\sigma \mathrm{H}_{\max }\right)$ is currently nearly E-W (Tsukahara and Kobayashi 1991; Terakawa and Matsu'ura 2010), and the conditions determined by inverting the fault-slip data from active faults that have exhibited cumulative displacement for the past $\sim 10^{5}$ years, it has been suggested that the stress field in central Japan has been uniform and stable for the past $\sim 10^{5}$ years (Tsutsumi et al. 2012). Wesnousky et al. (1982) estimated the geological horizontal shortening strain rate of central Japan, including in the Kinki region, to be $16-26 \times 10^{-9}$ /year, based on earthquake records with a magnitude of 6.9 or greater and the displacement 
rates of active faults for the last $\sim 400$ years. We first summarize the Quaternary geology in the Osaka Plain, especially that of the Osaka Group, Uemachi fault zone, and Ikoma fault zone, because these geological observations constrain the model parameters and results.

\section{Osaka Group}

The Osaka sedimentary basin is filled by the strata of the Plio-Middle Pleistocene Osaka Group, Middle-Upper Pleistocene terrace deposits and their corresponding sediments, and Upper Pleistocene-Holocene alluvium. The strata are 1000-2000 m thick at the depocenter and 200-400 m thick at the margins (Itihara 1993). Yoshikawa and Mitamura (1999) reported that the Quaternary system in the Osaka Plain consists of unconsolidated clay, silt, sand, and gravel layers with a thickness of more than $1500 \mathrm{~m}$ and dozens of volcanic ash layers; this system has been divided into the Miyakojima Formation in the lower part, the Tanaka Formation in the upper part, and the Namba Formation in the uppermost part (Fig. 1b). The Miyakojima Formation consists of fluvial deposits primarily composed of gravel, sand, and silt layers, whereas the Tanaka and Namba formations consist of river sand and gravel layers and 21 marine clay layers (Ma-1, Ma0, Ma0.5, Ma1, Ma1.3, Ma1.5, Ma1.7, Ma2, ..., Ma11 (1), Ma11 (2), Ma12, and Ma13 in ascending order). The Ma-1 marine clay has been assigned to marine isotope stage (MIS) 37, suggesting that the deposition of the Ma-1 was at 1.2 Ma (Yoshikawa and Mitamura 1999).

Many drilling and seismic reflection surveys have been conducted in the Osaka Plain, revealing details concerning its subsurface structure. Ikebe et al. (1970) analyzed nine deep drilling cores (OD-1-OD-9) and found that the Osaka Plain can be divided into two areas (i.e., west and east Osaka) by the $\mathrm{N}-\mathrm{S}$-trending Uemachi fault zone. The basement depth in west Osaka is more than $1000 \mathrm{~m}$ (because the OD-1 core did not reach basement rock at a depth of $907 \mathrm{~m}$ ), whereas the basement depth in the Uemachi Upland and its northern extension is as shallow as $656 \mathrm{~m}$ (OD-2; Fig. 1b). The basement depth in the central part of the Osaka Plain was examined based on the basement structures inferred from gravity anomalies
(Nakagawa et al. 1996a; Kansai Geo-informatics Council 1998) and reflection seismic surveys (Ikebe et al. 1970). Using this information, Uchiyama et al. (2001) and the Osaka Prefecture (2004) found that the depth of the basement surface in west Osaka is nearly $1500 \mathrm{~m}$ and does not significantly change to the west; meanwhile, in east Osaka, the depth is approximately $800 \mathrm{~m}$ near the Uemachi Upland and more than $1500 \mathrm{~m}$ near the Onchi River and the surface of the basement slopes to the east (Fig. 3). In addition, the strata thickness does not change in west Osaka, whereas the strata thickness in east Osaka tends to increase eastward (Uchiyama et al. 2001). In detail, in east Osaka, the thickness of the Miyakojima Formation is approximately $550 \mathrm{~m}$ at the Uemachi Upland and more than 700 m near the Onchi River and the thickness of the lower Tanaka Formation (Ma-1Ma6) is approximately $250 \mathrm{~m}$ at the Uemachi Upland and $850 \mathrm{~m}$ at the location of the OD-3 core site.

According to Uchiyama et al. (2001), the sedimentation rate from $\sim 1.2$ million to $\sim 0.05$ million years ago (Ma) in west Osaka, obtained from the OD-1 core, gradually decreased from 0.7 to $0.2 \mathrm{~m} / \mathrm{kyr}$ and the rate of the decrease in the sedimentation rate was higher after $\sim 0.4 \mathrm{Ma}$ (Fig. 4). In east Osaka, from $\sim 1.2$

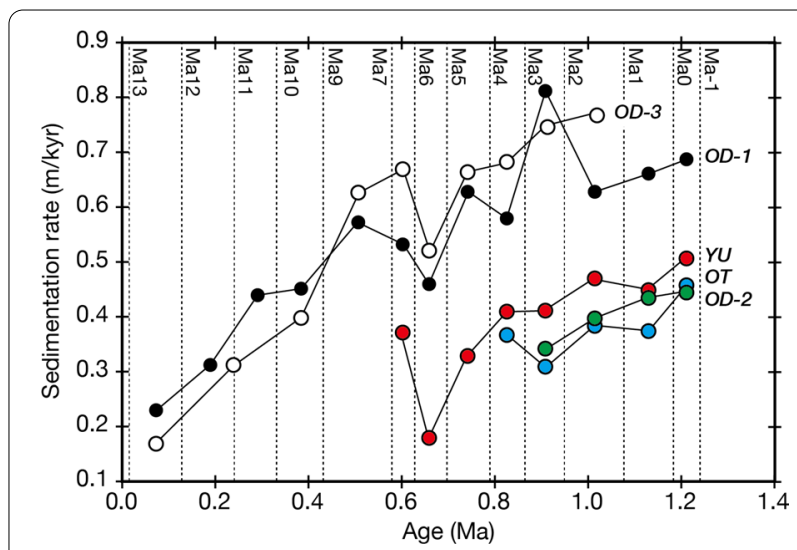

Fig. 4 Temporal variation of sedimentation rate at different core sites (Uchiyama et al. 2001)

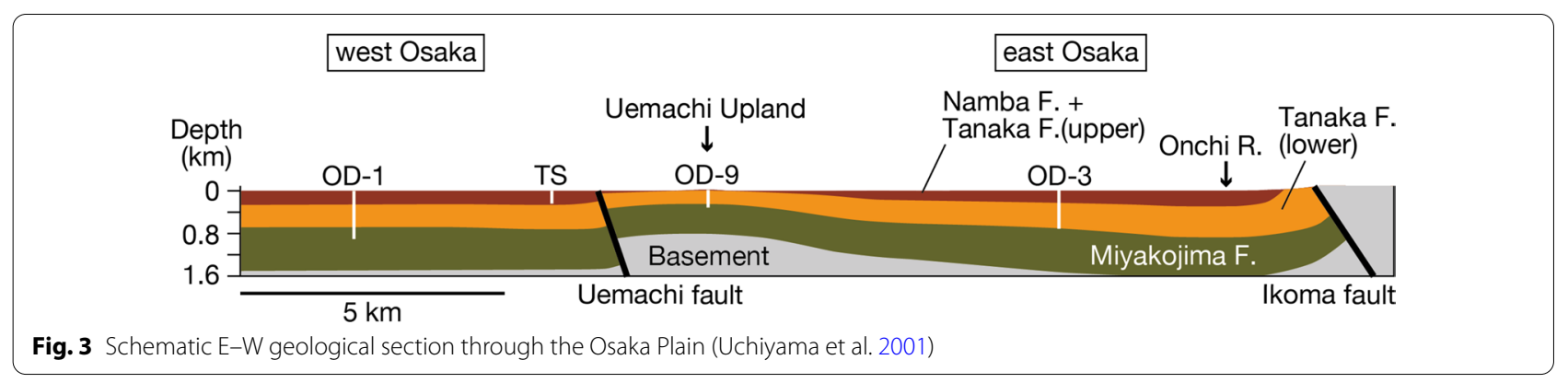


to $\sim 0.6 \mathrm{Ma}$ corresponding to the lower Tanaka Formation, the sedimentation rate decreases from $0.5 \mathrm{~m} / \mathrm{kyr}$ to $0.3 \mathrm{~m} / \mathrm{kyr}$ in the western region near the Uemachi Upland (OD-2, OD-9, and YU), whereas it decreases from 0.8 to $0.5 \mathrm{~m} / \mathrm{kyr}$ in the eastern region (OD-3). The Tanaka Formation around the Uemachi Upland is preserved in conformity only from the Ma3 layer to the Ma7 layer and is partially covered in an unconformity by the Ma12 layer. Suzuki (2016) estimated the sedimentation rate of the Miyakojima Formation to be $0.48 \mathrm{~m} / \mathrm{kyr}$ using the deep drilling core data of Yoshikawa et al. (2000).

\section{Uemachi fault zone}

The Uemachi fault zone is a nearly $\mathrm{N}$-S-striking fault system with a total length of $42 \mathrm{~km}$, including the Butsunenji-yama fault, Uemachi fault, Nagai fault, Sakamoto fault, Kumedaike fault, Sakuragawa flexure, and Suminoe flexure. It is a reverse fault in which the eastern side of the fault zone has moved upward relative to the western side (Nakata et al. 1996a, b; Okada and Togo 2000). It has been confirmed that the Uemachi fault zone has cut up to the Ma12 layer (Mitamura et al. 1994) and that the Holocene sediments near the surface are bent (Headquarters for Earthquake Research Promotion of MEXT 2004). The dip angle of the fault has been estimated to be $65^{\circ}-70^{\circ}$ (Headquarters for Earthquake Research Promotion of MEXT 2004), as inferred from topographical and geological features (Huzita and Kasama 1982) and the results of seismic reflection surveys (e.g., Sugiyama and Sangawa 1996; Sugiyama, 1997; Sugiyama et al. 2001, 2003). Based on the difference in the thickness of the Quaternary strata between the eastern and western sides of the Uemachi fault, the displacement rate of the Uemachi fault zone from 1.2 to $0.6 \mathrm{Ma}$ has been estimated to be $\sim 0.3 \mathrm{~m} /$ kyr (Uchiyama et al. 2001) while that from 0.6 to $0.15 \mathrm{Ma}$ has been estimated to be $\sim 0.4 \mathrm{~m} / \mathrm{kyr}$ (Headquarters for Earthquake Research Promotion of MEXT 2001).

Ishiyama (2003), based on the seismic reflection survey of Yoshikawa et al. (1987), interpreted the bending structure of the reflection section as a fault-propagation fold. Given that the Uemachi fault has a dip angle of $\sim 40^{\circ}$ and that there is $1 \mathrm{~km}$ of slip along the fault, he demonstrated, using the trishear fault-propagation fold model of Allmendinger (1998), that the sedimentary structure of the Ma-1 layer at the lowermost part of the Tanaka Formation can be reproduced. Furthermore, because the Osaka Group is thinner at the Uemachi Upland and thicker eastward, Ishiyama (2003) suggested that the Uemachi fault zone may be a thin-skinned thrust converging to a low-angle detachment in the upper crust (less than $5 \mathrm{~km}$; Fig. 2). Sato et al. (2009) interpreted the seismic reflection results to indicate that the Uemachi and Ikoma fault zones inclined to the east and that their low-angle detachment faults converge at a depth of approximately $10 \mathrm{~km}$, which is much deeper than the depth suggested by Ishiyama (2003). Iwasaki (2016) evaluated the dip angle of the Uemachi fault using PLAXIS ${ }^{\circledR}$, a finite element method ground analysis software. Given a displacement of several meters along the fault with a dip angle of $\sim 30^{\circ}$ and with the fault tip located $1000 \mathrm{~m}$ below the surface, the inclination angle of the axial plane of the Sakuragawa flexure $\left(65^{\circ}-70^{\circ}\right)$ can be reproduced.

\section{Ikoma fault zone}

The Ikoma fault zone is a nearly N-S-striking fault system with a total length of $38 \mathrm{~km}$. It is composed of the Ikoma fault, Katano fault, Hirakata fault, Taguchi fault, and Konda fault (Nakata et al. 1996a, b; Okada et al. 1996; Shimokawa et al. 1997; Sugiyama et al. 1999; Okada and Togo 2000). At the surface, the Ikoma fault is located $\sim 12 \mathrm{~km}$ east of the Uemachi fault (Fig. 1a). The Ikoma fault is an east-side-up reverse fault located near the boundary between the Osaka Plain and the Ikoma Mountains, which consist of rocks of the Ryoke belt (Horike et al. 1995; Nakata et al. 1996a, b; Shimokawa et al. 1997; Okada and Togo 2000). Using seismic reflection surveys at the Ikoma fault, Shimokawa et al. (1997) found that the Ikoma fault is inclined to the east at a moderate angle (approximately $30^{\circ}-40^{\circ}$ ) below a depth of $400 \mathrm{~m}$. Furthermore, they estimated the mean vertical displacement rate of the Ikoma fault system to be $0.5-1 \mathrm{~m} / \mathrm{kyr}$, as inferred from a trench survey. Ishiyama (2003) suggested that the high uplift rate of the Ikoma fault zone indicates thick-skinned trajectories. He also pointed out that the downward projection of the Uemachi fault zone roots into the Ikoma fault at the shallower portion of the crust, suggesting that the northern Uemachi fault zone and the Ikoma fault zone comprise a larger system of a west-verging active fold and thrust belt that accommodates E-W contraction within the upper crust and that the Uemachi fault zone is a leading edge of the thrust belt.

\section{Numerical simulations \\ Method}

Numerical simulations of a two-dimensional viscoelasto-plastic body were performed using the I2ELVIS code of Gerya and Yuen $(2003,2007)$ and Gerya (2010) for MATLAB ${ }^{\circledR}$, with the deviatoric strain rate, $\dot{\varepsilon}_{i j}$, including three components:

$$
\dot{\varepsilon}_{i j}=\dot{\varepsilon}_{i j \text { (viscous) }}+\dot{\varepsilon}_{i j(\text { elastic })}+\dot{\varepsilon}_{i j \text { (plastic) }},
$$

where 


$$
\begin{aligned}
& \dot{\varepsilon}_{i j \text { (viscous) }}=\frac{1}{2 \eta} \sigma_{i j}, \\
& \dot{\varepsilon}_{i j \text { (elastic) }}=\frac{1}{2 G} \frac{\mathrm{D} \sigma_{i j}}{\mathrm{D} t}, \\
& \dot{\varepsilon}_{i j \text { (plastic) }}=0 \text { for } \sigma_{\mathrm{II}}<\sigma_{\text {yield }}, \\
& \dot{\varepsilon}_{i j \text { (plastic) }}=\chi \frac{\sigma_{i j}}{2 \sigma_{\mathrm{II}}} \text { for } \sigma_{\mathrm{II}}=\sigma_{\text {yield }},
\end{aligned}
$$

where $\eta$ is the effective viscosity, $G$ is the shear modulus, $\mathrm{D} \sigma_{i j} / \mathrm{D} t$ is the objective co-rotational time derivative of the deviatoric stress component $\sigma_{i j}, \sigma_{\text {yield }}$ is the plastic yield strength for a given rock, $\sigma_{\mathrm{II}}=\left(1 / 2 \sigma_{i j} \sigma_{i j}\right)^{1 / 2}$ is the second deviatoric stress invariant, and $X$ is the plastic multiplier, which is a variable scaling factor connecting the components of the plastic strain rate $\dot{\varepsilon}_{i j \text { (plastic) with }}$ the local stress distribution in places where the yielding condition is reached.

The creep viscosity, $\eta_{\text {creep }}$, depending on the stress and temperature, is defined by the following power law equation:

$$
\eta_{\text {creep }}=1 / 2 \dot{\varepsilon}_{\mathrm{II}}^{(1-n) / n} A^{-1 / n} \exp (E / n R T),
$$

where $A$ is the pre-exponential factor $\left[/\left(\mathrm{Pa}^{n} \cdot \mathrm{s}\right)\right], n$ is the stress exponent, $E$ is the activation energy $[\mathrm{J} / \mathrm{mol}], T$ is the temperature $[\mathrm{K}]$, and $R$ is the gas constant $(8.314 \mathrm{~J} /$ $(\mathrm{K} \cdot \mathrm{mol})$ ). To yield an effective rheology, the Mohr-Coulomb law was simplified using the yield stress, $\sigma_{\text {yield }}$, criterion and implemented using a "Mohr-Coulomb viscosity", $\eta_{\mathrm{MC}}$, as follows:

$$
\eta_{\mathrm{MC}}=\sigma_{\text {yield }} /\left(2 \dot{\varepsilon}_{\mathrm{II}}\right)
$$

where $\dot{\varepsilon}_{\mathrm{II}}=\left(1 / 2 \dot{\varepsilon}_{i j} \dot{\varepsilon}_{i j}\right)_{1 / 2}$ is the second invariant of the strain rate tensor. The yield stress or plastic strength, $\sigma_{\text {yield }}$, of a rock generally depends on the mean stress on the solids, $P$, such that

$$
\sigma_{\text {yield }}=C+\sin (\varphi) P,
$$

where $C$ is the cohesion (the residual strength at pressure $P=0)$ and $\phi$ is the effective internal friction angle. The effective viscosity, $\eta$, is then defined using the following criterion:

$$
\begin{aligned}
& \eta=\eta_{\text {creep }}, \text { when } 2 \dot{\varepsilon}_{\mathrm{II}} \eta_{\text {creep }}<\sigma_{\text {yield }}, \\
& \eta=\eta_{\mathrm{MC}}, \text { when } 2 \dot{\varepsilon}_{\mathrm{II}} \eta_{\text {creep }}>\sigma_{\text {yield }}
\end{aligned}
$$

In this study, for the sediment layer and the upper basement layer (i.e., the upper crust), we used the flow law parameters for wet quartz $\left(A=4.0 \times 10^{-11.2} /\left(\mathrm{MPa}^{n} \cdot \mathrm{s}\right)\right.$, including the effect of a constant water fugacity of $4 \mathrm{MPa}$ at $T=473 \mathrm{~K}$ and $P=200 \mathrm{MPa}, n=4$, and $E=135 \mathrm{~kJ} /$ mol; Hirth et al. 2001), and for the lower basement layer (i.e., the lower crust), we used the flow law parameters for wet plagioclase $\left(\mathrm{An}_{60}\right) \quad\left(A=1.0 \times 10^{-1.5} /\left(\mathrm{MPa}^{n} \cdot \mathrm{s}\right)\right.$, $n=3$, and $E=235 \mathrm{~kJ} / \mathrm{mol}$; Rybacki and Dresen 2004). To incorporate the effect of strain weakening, it is modeled as a linear decrease of friction angle and cohesion between accumulated strain of $\varepsilon_{\mathrm{II}}=0$ and $\varepsilon_{\mathrm{II}}=1$ (Fig. 5). These lower and upper thresholds of strain for weakening activation and completion are similar to those in previous numerical investigations of strain weakening of crustal rocks (e.g., Allken et al 2012; Ruh et al. 2014; Döhmann et al. 2019). At $\varepsilon_{\mathrm{II}}<1$, the cohesion and friction angle change linearly from the initial cohesion $\left(C_{i}\right)$ and initial friction angle $\left(\phi_{i}\right)$ to the weakened cohesion $\left(C_{w}\right)$ and weakened friction angle $\left(\phi_{w}\right)$, respectively, whereas at $\varepsilon_{\mathrm{II}} \geq 1$, the cohesion and friction angle are constant at $C_{w}$ and $\phi_{w}$. For the basement layer, $C_{i}$ and $C_{w}$ are $10^{7} \mathrm{~Pa}$ and $10^{6} \mathrm{~Pa}$, respectively, and $\phi_{i}$ and $\phi_{w}$ are $35^{\circ}$ (initial friction coefficient $\mu_{i}=\tan \left(\phi_{i}\right)=\sim 0.7$ ) and $27^{\circ}$ (weakened friction coefficient $\left.\mu_{w}=\tan \left(\phi_{w}\right)=\sim 0.5\right)$, respectively. The value of the weakened friction coefficient corresponds to the experimentally determined values for phyllosilicate minerals, i.e., mica and chlorite (Morrow et al. 2000; Ikari et al. 2011), and the value for damage zones of the San Andreas fault (Carpenter et al. 2015). For the sediment layer, according to Mannu et al. (2016), the physical properties of $C_{i}=C_{w}=10^{6} \mathrm{~Pa}, \phi_{i}=14^{\circ}$, and $\phi_{w}=6^{\circ}$ are employed for the calculation. The shear modulus $G$ of the upper basement layer and the sediment layer is $1.0 \times 10^{10} \mathrm{~Pa}$, and that of the lower basement layer is $2.5 \times 10^{10} \mathrm{~Pa}$ (Table 17.2 of Gerya 2010).

An energy conservation law that does not consider internal heat generation can be expressed as.

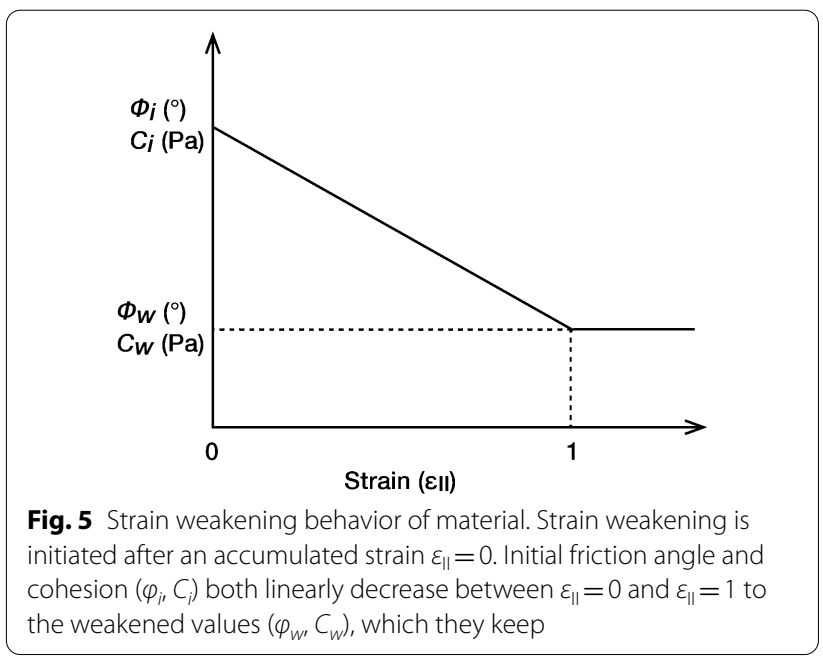




$$
\begin{gathered}
\rho C_{p} \frac{\mathrm{D} T}{\mathrm{D} t}=\frac{\partial q_{x}}{\partial x}+\frac{\partial q_{z}}{\partial z}, \\
q_{x}=k \frac{\partial T}{\partial x}, q_{z}=k \frac{\partial T}{\partial z}
\end{gathered}
$$

where $q_{x}$ and $q_{z}$ are the conductive heat fluxes in the horizontal and vertical directions, respectively, $t$ is time $[\mathrm{s}], \rho$ is the local density depending on the composition, $C_{p}$ is the specific heat at constant pressure, and $k$ is the thermal conductivity. According to Gerya et al. (2009) and Gerya (2010), the values of $C_{p}$ for the sedimentary layer and the basement are set to $1000 \mathrm{~J} /(\mathrm{kg} \cdot \mathrm{K})$ and the value of $k$ [W/(m.K)] for the sedimentary layer and the upper basement is $0.64+807 /(T+77)$ while that for the lower basement is $1.18+474 /(T+77)$.

Conservation of mass is approximated by the incompressible time-dependent two-dimensional continuity equation:

$$
\frac{\partial v_{x}}{\partial x}+\frac{\partial v_{z}}{\partial z}=0
$$

where $v_{x}$ and $v_{z}$ are the horizontal and vertical components of the velocity vector, respectively.

The two-dimensional Stokes equations for creeping flow are

$$
\begin{aligned}
& \frac{\partial \sigma_{x x}}{\partial x}+\frac{\partial \sigma_{x z}}{\partial z}=\frac{\partial P}{\partial x}, \\
& \frac{\partial \sigma_{z x}}{\partial x}+\frac{\partial \sigma_{z z}}{\partial z}=\frac{\partial P}{\partial z}-\rho g,
\end{aligned}
$$

where $g$ is the gravitational acceleration $\left(9.81 \mathrm{~m} / \mathrm{s}^{2}\right)$. In this study, the densities of the sediment, upper basement, and lower basement are $2600 \mathrm{~kg} / \mathrm{m}^{3}, 2700 \mathrm{~kg} / \mathrm{m}^{3}$, and $2800 \mathrm{~kg} / \mathrm{m}^{3}$, respectively. A weak layer above the lithosphere ("sticky air", $\eta=10^{18} \mathrm{~Pa} \mathrm{~s}, \rho=1 \mathrm{~kg} / \mathrm{m}^{3}, k=300 \mathrm{~W} /$ $\left.(\mathrm{m} \cdot \mathrm{K}), C_{p}=3.0 \times 10^{6} \mathrm{~J} /(\mathrm{kg} \cdot \mathrm{K})\right)$ provides a free-surfacelike condition (Gerya 2010).

The calculation domain in the initial state was $80 \mathrm{~km} \times 35 \mathrm{~km}$ (Fig. 6) and consisted of the layer of sticky air and the upper and lower basement layers. The sediment layer is not included in the model layers at the initial state. The crustal strength profile with strain rate of $5 \times 10^{-16} / \mathrm{s}$ and the temperature profile at the initial state in the numerical model are illustrated in the inset of Fig. 6. The frictional-viscous transition zone is located at the depth of $\sim 8 \mathrm{~km}$. Below this transition zone, rocks behave in an increasingly ductile manner. All models used a finite-difference with marker-in-cell technique and were conducted on a fully staggered rectangular Eulerian grid with 4,480,000 markers. The grid spacing

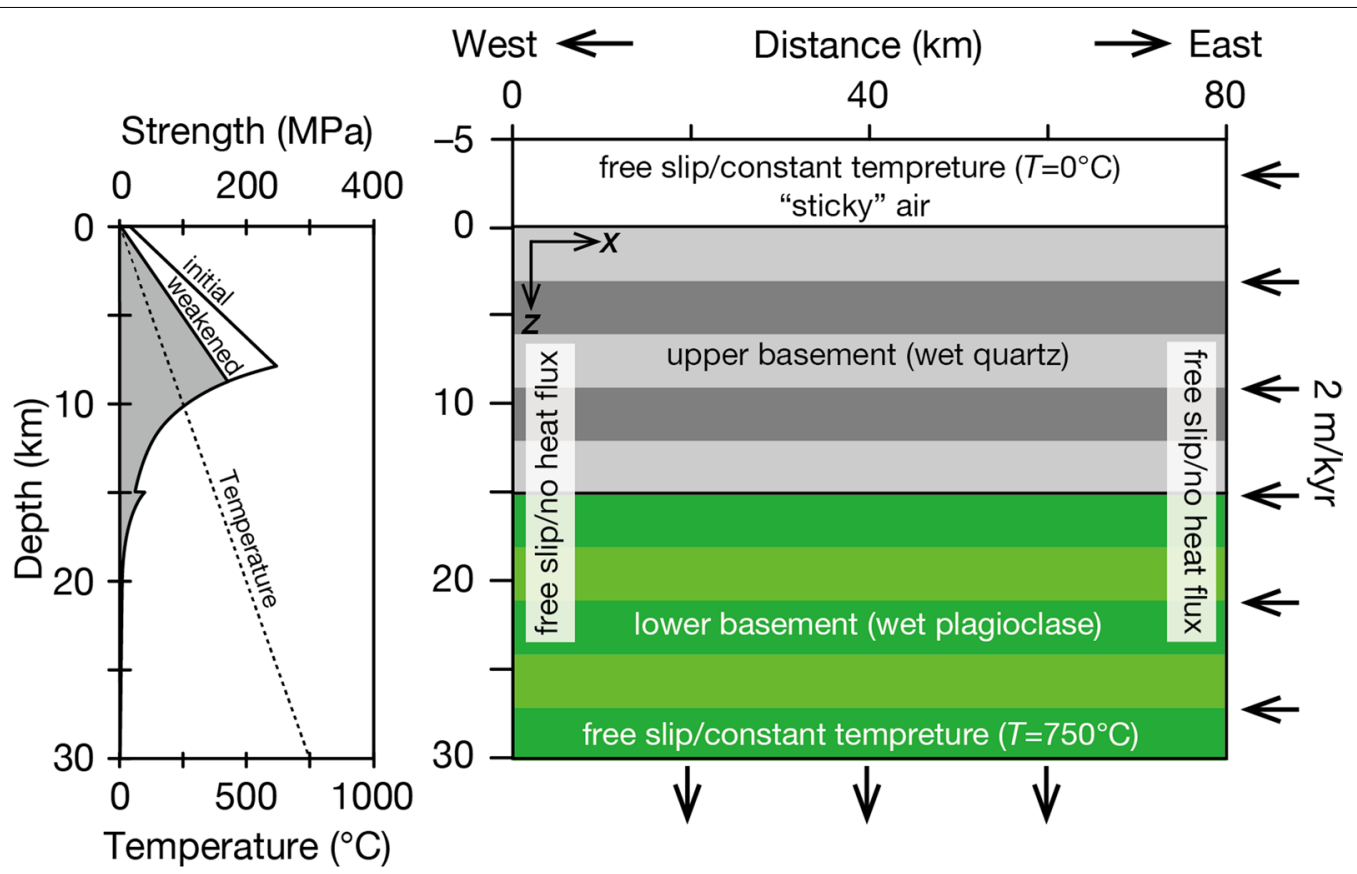

Fig. 6 Model geometry and boundary conditions. A constant horizontal velocity $(2 \mathrm{~m} / \mathrm{kyr}$ ) and a changing downward velocity (from $0.88 \mathrm{~m} / \mathrm{kyr}$ at $0 \mathrm{Myr}$ to $1.02 \mathrm{~m} / \mathrm{kyr}$ at $3 \mathrm{Myr}$ ) are applied at the right and bottom boundaries, respectively. The inset shows the crustal strength profile (solid lines and curves), with the strain rate $(\dot{\varepsilon})$ of $5 \times 10^{-16} / \mathrm{s}$, the initial friction coefficient $\left(\mu_{i}\right)$ of 0.7 and the weakened friction coefficient $\left(\mu_{w}\right)$ of 0.5 , and temperature profile (dashed line) at the initial state in the numerical model 
was not uniform and was initially applied as an $800 \times 210$ grid of $80 \mathrm{~km} \times 21 \mathrm{~km}$ in the upper domain and as an $800 \times 60$ grid of $80 \mathrm{~km} \times 14 \mathrm{~km}$ in the lower domain. The grid spacing was recalculated at each time step to accommodate the horizontal shortening described below. In the marker-in-cell technique, to minimize a numerical diffusion, properties are initially distributed on a large amount of Lagrangian points that are advected according to a computed velocity field. To compute the velocity field on the Eulerian grid, material properties are interpolated from the Lagrangian points to the Eulerian grid using weighted-distance averaging. The initial position of each marker was set at a regular interval and a small fluctuation was added using the MATLAB ${ }^{\circledR}$ random number generator to avoid causing a moiré pattern in a distribution of material properties on the grid. A small difference in initial position of markers causes a difference in material properties on the grid, and thus in computed velocity field. This makes a difference, especially in the case of a nucleation of localized strained zones. In some cases, we changed the seed for the random number generator to evaluate the effect of the initial position of the markers. The absolute time step was $10 \mathrm{kyr}$. The calculation time was set to $3 \mathrm{Myr}$ according to the fission track age (2.71 million years ago; Itihara et al. 1984) of the volcanic ash layer at the bottom of the Osaka Group, and the onset of horizontal compression is defined as $t=0 \mathrm{Myr}$.

We applied free-slip conditions at all boundaries and constant leftward and downward velocities at the right and bottom boundaries, respectively. Temperatures at the top and bottom boundaries were constant, i.e., $0{ }^{\circ} \mathrm{C}$ and $7500^{\circ} \mathrm{C}$, respectively, and the right and left boundaries were insulated (no heat flux). An initial geothermal gradient of $25^{\circ} \mathrm{C} / \mathrm{km}$ (e.g., Okubo et al. 2005) was applied to the basement layer, whereas there was no temperature gradient in the sticky air layer (i.e., the temperature at the top of the basement layer was also $0{ }^{\circ} \mathrm{C}$ ). Following the horizontal shortening strain rate $\left(16-26 \times 10^{-9} /\right.$ year $)$ for central Japan of Wesnousky et al. (1982), the horizontal shortening rate was set to $2 \mathrm{~m} / \mathrm{kyr}$ (Fig. 6). Therefore, at the end of the calculation (3 Myr), the $80-\mathrm{km}$-wide crust was shortened by $6 \mathrm{~km}$. To conserve mass in the calculation domain, a changing downward velocity (from $0.88 \mathrm{~m} / \mathrm{kyr}$ at $0 \mathrm{Myr}$ to $1.02 \mathrm{~m} / \mathrm{kyr}$ at $3 \mathrm{Myr}$ ) was applied at the bottom boundary.

To model preexisting faults, strained zones with a strain, $\varepsilon_{\mathrm{II}}$, of 1 , having the initial $C_{w}$ and $\phi_{w}$, and a yield stress or plastic strength weaker than the surrounding rock mass were applied in the basement layer as highstrained weak zones. In this study, we refer to such highstrained weak zones as "faults" or "fault zones". Even though the width of a preexisting fault zone was set to $250 \mathrm{~m}$, that is, 2.5 times wider than the grid space, the width of the zone follows the scaling law of the linear relationship between the width of the fault process zone and the fault length with a proportionality constant on the order of $10^{-2}$ (Vermilye and Scholz 1998).

We applied several assumptions in our model. Because the Osaka Group consist of fluvial and shallow marine deposits, we assumed that the sedimentation rate was nearly equal to the subsidence rate for a time scale longer than the cycle of glacial eustasy $(\sim 100 \mathrm{kyr})$. We also assumed that the subsidence and uplifting was caused by two processes: (1) the average change across the studied area, which was a part of crustal movement of a larger area, and (2) the change due to fault displacement and tilting of faulted block. Our model calculated the second process dynamically. To model the sedimentation, the sea level rise (or drop) was introduced instead of adding subsidence (or uplifting) due to the process (1). The rate of sea level change was determined so that the sum of the dynamically computed subsidence rate and the rate of sea level change is equal to the geologically observed sedimentation rate at the location of the OD- 1 core site. Therefore, the sea level changes to reproduce the sedimentation rate at the location of the OD- 1 core site, but is not controlled by the global eustatic sea level change. At the initial state, the sea level was set to the boundary between the sticky air and the basement layer. At each time step, we changed the sea level and the markers of the sticky air below the sea level were replaced with markers of the sedimentary layer, i.e., a space below the new sea level was totally filled with new sediments. Surface erosion was not considered in this study.

We considered three types of cases with the simulation model: (1) cases without any preexisting fault zone; (2) cases with a single fault zone cutting the upper $12 \mathrm{~km}$ of the basement layer; and (3) cases with two preexisting fault zones corresponding to the Uemachi and Ikoma fault zones. In the following section, we will describe the general model behavior based on the simulation results for the cases with or without a preexisting fault zone, and the application to the Osaka Plain based on the results for the cases with two preexisting fault zones.

\section{Results \\ General model behavior: cases with or without a preexisting fault zone}

In the cases without any preexisting fault, we did not consider sedimentation processes. Under the compressive stress field, the upper and lower basement layers deform homogeneously prior to $\sim 0.5 \mathrm{Myr}$ elapsed after the onset of horizontal compression $(t=0 \mathrm{Myr})$, whereas after 0.5 Myr, in the upper basement layer, the strain is concentrated into narrow zones and localized highstrained zones, i.e., newly formed thrust faults, develop 

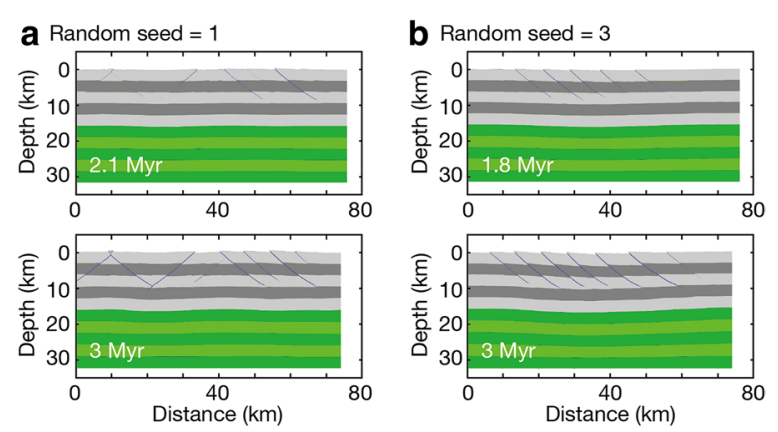

Fig. 7 Results for the numerical simulations without any preexisting fault zone. The newly formed faults (markers with a cumulative strain larger than 1) are illustrated in dark blue. a Case with the random seed number $=1$. $\mathbf{b}$ Case with the random seed number $=3$

as a result of compression (Fig. 7). These cases demonstrate that simulation results with different random seeds at $3 \mathrm{Myr}$ differ somewhat with respect to the dip directions of the newly formed thrust faults. The thrust faults grow downward from the surface because values of the yield stress $\sigma_{\text {yield }}$ of a rock given by Eq. (4) are low at shallower depths. Above the frictional-viscous transition zone, the strain is accommodated primarily by frictional deformation with weakened friction $\left(\mu_{w}\right)$ relative to the viscous deformation (inset in Fig. 6), so that the thrust faults develop from the surface to the frictional-viscous transition zone. The dip angles of the faults are $\sim 30^{\circ}-40^{\circ}$ near the surface, but bend gently near the frictional-viscous transition depth. These fault geometries (i.e., dip angles of the faults) are not explicitly "determined" by the code, but form spontaneously during the propagation of the high-strained zone involving markers for which the yielding condition given by Eq. (4) is satisfied locally. The dip angles of the faults are consistent with the theoretical dip angles of shear bands in compressional setting ranging between $45^{\circ}$ (Roscoe angle) and $45^{\circ}-\phi / 2$ (Coulomb angle) (Vermeer 1990; Kaus 2010). With increasing the amount of horizontal shortening, the thickness of the early formed faults widens and becomes $\sim 300-500 \mathrm{~m}$ at 3 Myr; however, the depth of the fault tips does not change significantly after $\sim 2$ Myr. In the lower basement layer, the strain is distributed to form large-scale folds instead of localized high-strained zones. The displacement along the faults leads to relative subsidence on the lower side of the faults or uplifting on the upper side. In general, the amount of vertical displacement decreases with distance from the faults. The blocks between faults with the same dip direction tilt antithetically (Fig. 7b), whereas the blocks between faults with opposite dip directions rise or sink vertically (Fig. 7a).
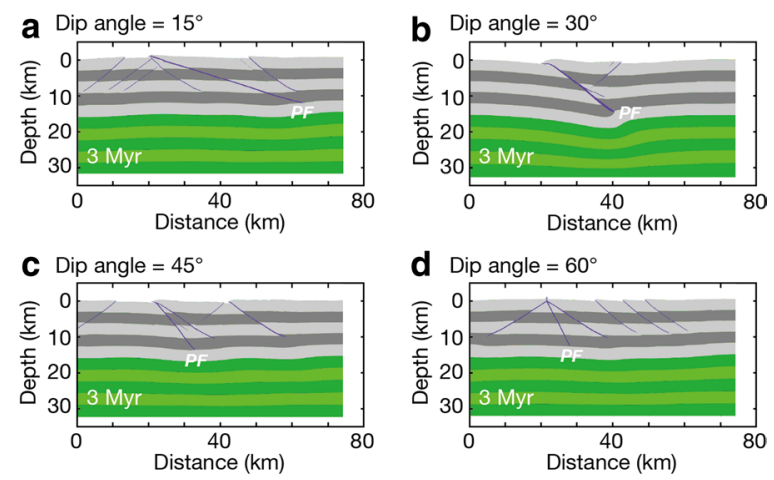

d Dip angle $=60^{\circ}$

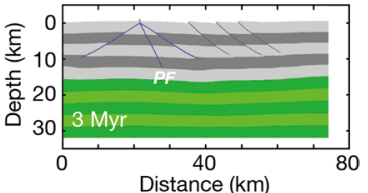

Fig. 8 Results for numerical simulations with a single preexisting fault zone. The preexisting fault (PF) and the newly formed faults (markers with a cumulative strain larger than 1) are illustrated in dark blue. The weakened friction coefficient $\mu_{w}$ is $\sim 0.5$ (weakened friction angle $\varphi_{w}=27^{\circ}$. . a Case with a dip angle of $15^{\circ}$. b Case with a dip angle of $30^{\circ}$. c Case with a dip angle of $45^{\circ}$. $\mathbf{d}$ Case with a dip angle of $60^{\circ}$

In the cases with a single preexisting fault, we did not consider sedimentation processes. We set the fault to have different dip angles (i.e., $15^{\circ}, 30^{\circ}, 45^{\circ}$, and $60^{\circ}$ ) at the surface location of $x=23 \mathrm{~km}$. Based on the simulation results for the cases with no preexisting fault, because the local displacements in the strained zone in the deepest part of the upper basement layer and the lower basement layer are negligible, we considered the faults as only preexisting above $12 \mathrm{~km}$. In this case, the effect of changing the random seed for the initial marker distribution is smaller than in the cases without a preexisting fault and we only show the results with the random seed $=1$ in Fig. 8. In all the cases, at the initial stage, strain localization occurs in the preexisting fault zone as expected. The zone widens and becomes a source for newly generated spray fault zones. Displacement occurs along the preexisting faults in the upper basement layer for dip angles of $15^{\circ}-45^{\circ}$ but not $60^{\circ}$ (Fig. 8). When the dip angle of the preexisting fault is $15^{\circ}$ or $45^{\circ}$, the displacement along the preexisting fault is relatively small and new high-strained zones with dip angles of $\sim 30^{\circ}-40^{\circ}$ develop. The preexisting fault steepens by $\sim 2-5^{\circ}$ because of the rotation of the fault during horizontal shortening. When the dip angle of the preexisting fault is $30^{\circ}$, which is suitable for horizontal compression, the displacement along the fault is significant and the fault ultimately steepens by $\sim 7^{\circ}$ as a result of the horizontal shortening and the tilting of the upper basement layer. After the preexisting fault becomes steeper, new faults with dip angles of $\sim 30^{\circ}-40^{\circ}$ are formed. Conversely, when the dip angle of the preexisting fault is $60^{\circ}$, many new faults with dip angles of $\sim 30^{\circ}-40^{\circ}$ are formed and evenly displaced; in this case, the preexisting fault ultimately steepens by $\sim 2^{\circ}$. 
When the faults contain large amounts of clay minerals, the experimentally derived friction coefficient for the fault zone decreases significantly (Takahashi et al. 2007; Ikari et al. 2011). We performed a simulation for a single preexisting fault zone with lower friction values of $\mu_{w}=\sim 0.4$ and $\sim 0.3\left(\phi_{w}=22^{\circ}\right.$ and $17^{\circ}$, respectively). Figure 9 shows the results of the effect of the different weakened friction values on the activity of a preexisting fault with a dip angle of $60^{\circ}$. In this case, the preexisting fault, which is not favorably oriented to the horizontal compressional stress field, is active under the condition of $\mu_{w}<0.4$.

In summary, based on the results for the cases with or without a preexisting fault, when the friction coefficient of the faults is $\sim 0.5$, we found as general model behavior that (1) the localized high-strained zones (i.e., faults) develop from the surface to the frictional-viscous transition zone ( $12 \mathrm{~km}$ depth); (2) the dip angles of the faults are $\sim 30^{\circ}-40^{\circ}$ near the surface, which are consistent with the theoretical dip angles of shear bands in compressional setting, but bend gently near the frictional-viscous transition depth; (3) the blocks between faults with the same dip direction tilt antithetically, whereas the blocks between faults with opposite dip directions rise or sink vertically; and (4) displacement along the preexisting fault with a dip angle of $30^{\circ}$ in the upper basement layer is much larger than that along the preexisting faults with lower and higher dip angles (i.e., $15^{\circ}, 45^{\circ}$, and $60^{\circ}$ ).

\section{Application to the Osaka Plain: cases with two preexisting fault zones}

In the cases with two preexisting faults, we consider the sedimentation process. We set two faults, whose locations at the surface were $x=23 \mathrm{~km}$ (i.e., the western fault) and $x=40 \mathrm{~km}$ (i.e., the eastern fault). The western and eastern faults correspond to the Uemachi and Ikoma faults, respectively, which are separated by $\sim 14 \mathrm{~km}$ at the surface in the final state. At the location equivalent to $x=18 \mathrm{~km}$ in the initial state, corresponding to the OD-1 core site, which is $\sim 5 \mathrm{~km}$ west of the Uemachi fault, we
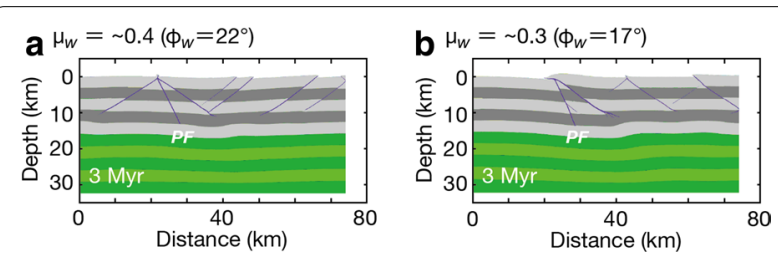

Fig. 9 Effect of different weakened friction coefficients $\mu_{w}$ on the activity of a preexisting fault with a dip angle of $60^{\circ}$. a Case with $\mu_{w}=\sim 0.4$ (weakened friction angle $\varphi_{w}=22^{\circ}$ ). $\mathbf{b}$ Case with $\mu_{w}=\sim 0.3$

$\left(\varphi_{w}=17^{\circ}\right)$. The preexisting fault (PF) and newly formed faults (markers with a cumulative strain larger than 1) are illustrated in dark blue set the mean sedimentation rate to deposit $900 \mathrm{~m}$ of the Miyakojima Formation and $650 \mathrm{~m}$ of the Tanaka and Namba formations (i.e., $0.5 \mathrm{~m} / \mathrm{kyr}$ from 0 to $1.8 \mathrm{Myr}$, $0.6 \mathrm{~m} / \mathrm{kyr}$ from 1.8 Myr to $2.6 \mathrm{Myr}$, and $0.4 \mathrm{~m} / \mathrm{kyr}$ from 2.6 Myr to 3.0 Myr). Because Quaternary sediments are basically absent in the Ikoma Mountains (with a highest elevation of $642 \mathrm{~m}$ ), the Ikoma Mountains may have been separated from the marine waters at 3 million years ago (Ma). However, because the elevation of the Ikoma Mountains at $3 \mathrm{Ma}$ is unknown, the elevation of the Ikoma Mountains was assumed to be $0 \mathrm{~m}$ at $3 \mathrm{Ma}$ (at 0 Myr in this study). According to the results for the cases with a single fault zone (Fig. 8), the optimal dip angle for the resolved shear stress is $\sim 30^{\circ}-40^{\circ}$ and the dip angles of the western and eastern faults should also be $\sim 30^{\circ}-$ $40^{\circ}$. Based on the geological observations, because the vertical displacement rate related to the Ikoma fault has been estimated to be much higher than that related to the Uemachi fault (Table 1), the dip angle of the western fault was set to differ slightly from the optimal value for the resolved shear stress, or the friction coefficients for the eastern fault were set to be lower than those for the western fault. Because previous studies have generally suggested that the dip angle of the Uemachi fault is steeper than that of the Ikoma fault (Fig. 2) and because the dip angle of the Uemachi fault was recently estimated to be $\sim 40^{\circ}$ (Kato and Ueda 2019), we applied dip angles of $40^{\circ}$ and $30^{\circ}$ to the western and eastern faults, respectively (Fig. 10a).

We compared the simulation results and geologic structures proposed by Uchiyama et al. (2001, Fig. 3) based on the following points: (1) the large-scale variation in the thickness of the upper and uppermost sedimentary layers, corresponding to the Tanaka and Namba formations, in the area in-between the western and eastern faults, i.e., in east Osaka, especially at the location of the OD-9 core site $(\sim 2 \mathrm{~km}$ east from the Uemachi fault at the final state) in the Uemachi Upland and at the location of the OD-3 core site ( $\sim 9 \mathrm{~km}$ east from the Uemachi fault at the final state), and (2) the vertical displacement rates after 1.8 Myr, corresponding to the sedimentation period of the Tanaka and Namba formations, estimated by the vertical differences between the highest point of the hanging wall basement and the lowest point of the footwall basement near the western and eastern faults.

The displacement along the western and eastern faults leads to relative subsidence on the lower side of the faults, so that sediment layers form in the relative subsidence regions (Fig. 10a). The surface of the basement slopes to the east as a whole, and an eastward thickening of the sedimentary layers throughout the Osaka Plain is observed. These layers result from the displacement along the eastern fault being much larger than that 


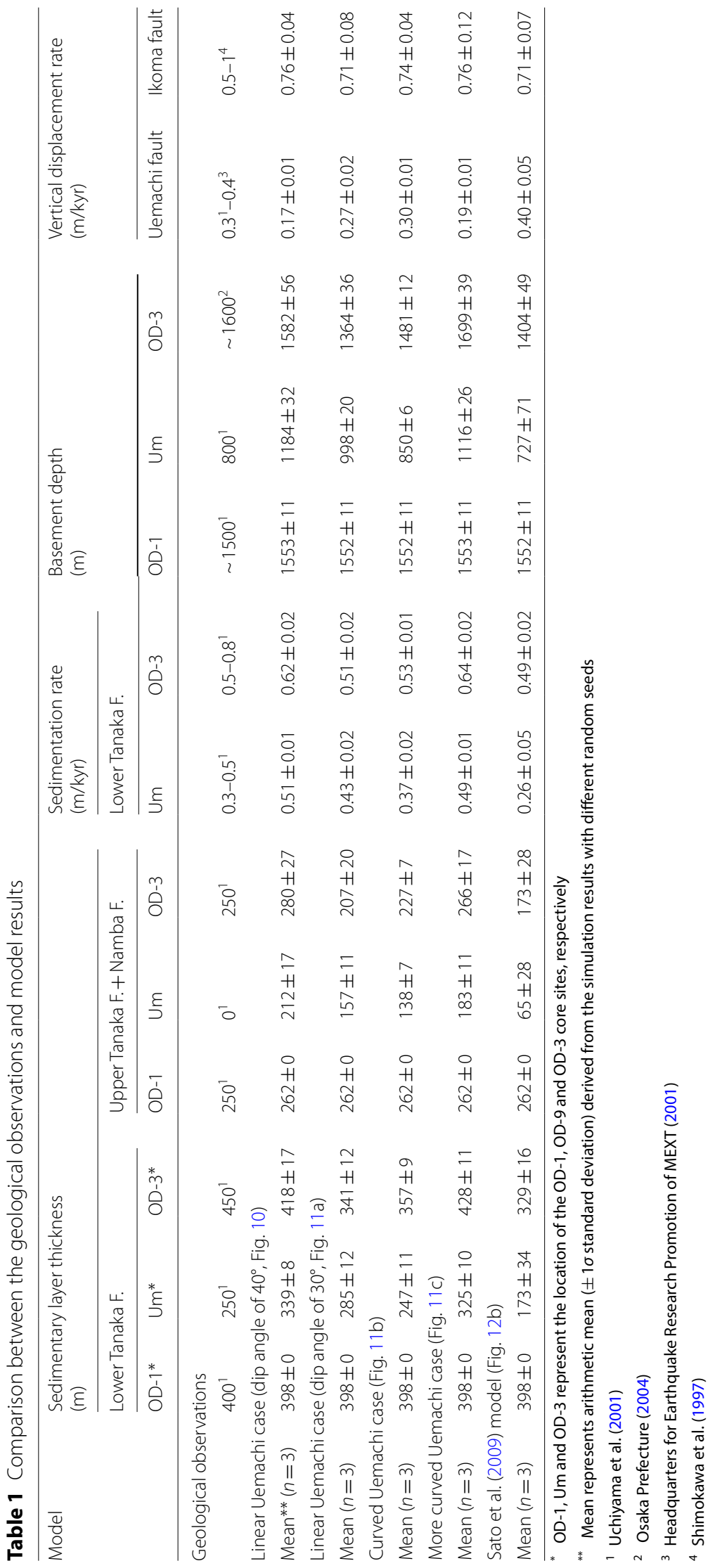




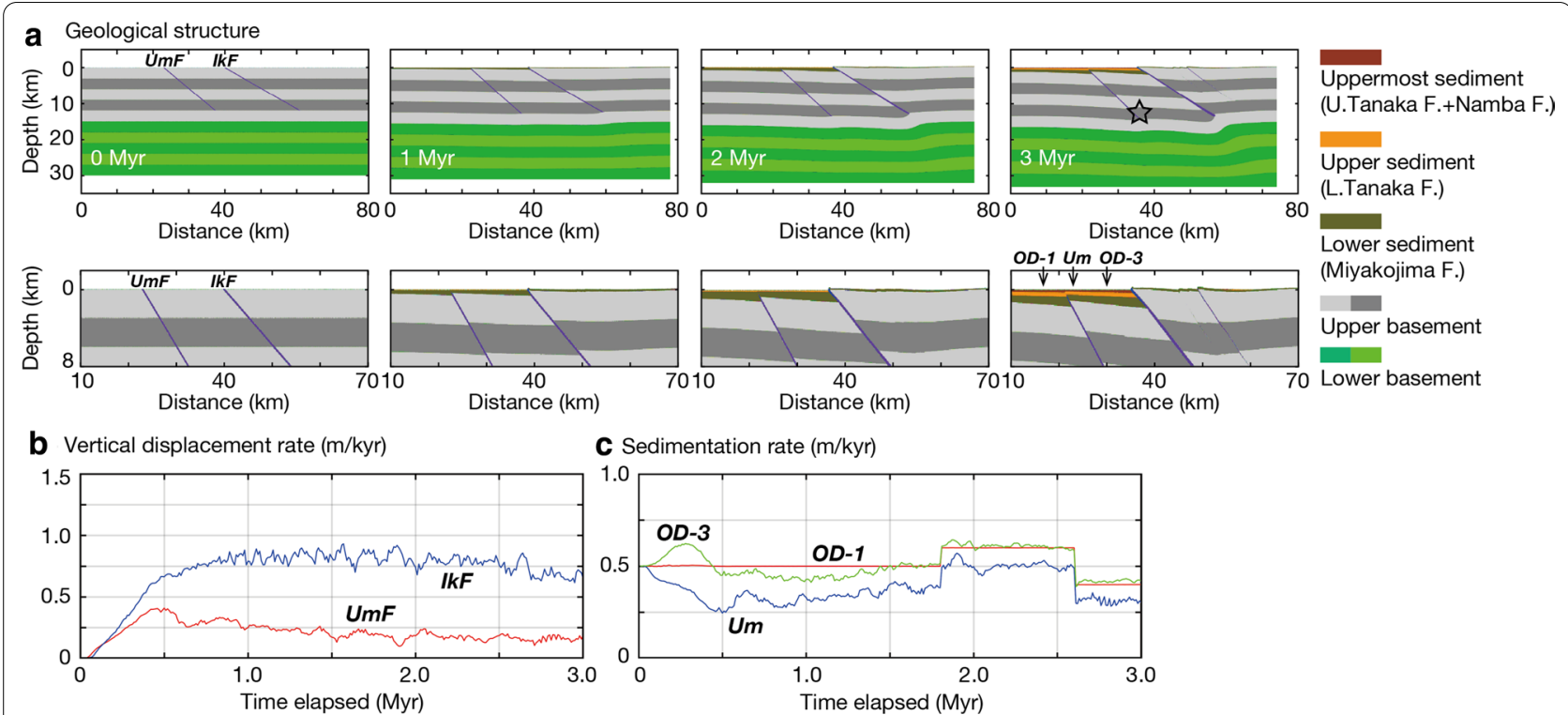

Fig. 10 Results of the numerical simulation for a case with two preexisting fault zones with dip angles of $40^{\circ}$ and $30^{\circ}$, corresponding to the Uemachi and Ikoma faults in the Osaka Plain, respectively. a The initial model geometry and time evolution. The hypocenter of the 2018 northern Osaka earthquake (Kato and Ueda 2019), located $12 \mathrm{~km}$ beneath the surface position $14 \mathrm{~km}$ east from the Uemachi fault, is indicated by a star. The lower panels show a close-up view of a $60 \mathrm{~km} \times 10 \mathrm{~km}$ domain including the western and eastern weak zones. The preexisting faults and newly formed faults (markers with a cumulative strain larger than 1) are illustrated in dark blue. OD-1, Um and OD-3 indicate the location of the OD-1, OD-9 and OD-3 core sites, respectively. b Time evolution of the vertical displacement rates along the western and eastern faults. c Time evolution of the sedimentation rates in the Uemachi Upland (i.e., at the location of the OD-9 core site) and at the location of the OD-3 core site. The imposed sedimentation rates at the location of the OD-1 core site are also shown

along the western fault (Table 1). As described in the "Method" section, the initial position of each marker was set at a regular interval and a small fluctuation was added using the MATLAB ${ }^{\circledR}$ random number generator and the initial position of the markers affect the model result. In Table 1, we show the effect of the initial position of the markers as standard deviation $(1 \sigma)$ derived from the simulation results with different random seeds, and in many cases standard deviation is less than $10 \%$ of the mean. Although the region west of the eastern fault is tilted eastward as a whole, the inclination of the basement slope in east Osaka is slightly steeper than that in west Osaka, due to the clockwise rotation of the east Osaka block arising from the displacement along the synthetic eastern and western faults. As shown in Fig. 10b, the vertical displacement rates related to the western and eastern faults increase monotonically prior to $\sim 0.5$ Myr. At the initial stage ( $<\sim 0.5 \mathrm{Myr})$ of the simulation, the deformation does not concentrate along the entire fault; the deformation front moves downward along the fault, and then the entire fault deforms after $\sim 0.5 \mathrm{Myr}$. Therefore, the monotonical increase in the displacement rate at the initial stage of the simulation results from the increase in the deforming length along the faults. The vertical displacement rate related to the eastern fault increases to $\sim 0.8 \mathrm{~m} / \mathrm{kyr}$ at $\sim 1 \mathrm{Myr}$ and becomes stable, whereas that along the western fault increases to $\sim 0.4 \mathrm{~m} /$ kyr at 0.5 Myr and then decreases. This implies that the deformation of the eastern fault is predominant after $\sim 0.5$ Myr. The mean vertical displacement rates along the western and eastern faults for the last $1 \mathrm{Myr}$ are $\sim 0.2 \mathrm{~m} / \mathrm{kyr}$ and $\sim 0.8 \mathrm{~m} / \mathrm{kyr}$, respectively (Fig. $10 \mathrm{~b}$ and Table 1). The mean displacement rate along the western fault is much slower than the geologically inferred displacement rate along the Uemachi fault $(\sim 0.3-0.4 \mathrm{~m} /$ kyr; Uchiyama et al. 2001; Headquarters for Earthquake Research Promotion of MEXT 2001), whereas that along the eastern fault corresponds to the geologically inferred displacement rate along the Ikoma fault $(0.5-1 \mathrm{~m} / \mathrm{kyr}$; Shimokawa et al. 1997).

The computed depth of the basement surface is approximately $1200 \mathrm{~m}$ at the location of the OD-9 core site in the Uemachi Upland and approximately $1600 \mathrm{~m}$ at the location of the OD-3 core site (Table 1); the former is deeper than the geologically inferred value $(800 \mathrm{~m})$ and the latter is comparable with the geological interpretation $(\sim 1600 \mathrm{~m})$. The thickness of the sediment layer, corresponding to the Tanaka and Namba formations, increases eastward; it is $\sim 550-\mathrm{m}$ thick in the Uemachi Upland and $\sim 700-\mathrm{m}$ thick at the location of the OD-3 core site. The result in the Uemachi Upland is thicker than the geologically inferred value $(250 \mathrm{~m})$, whereas that at the 
location of the OD-3 core site is comparable with geologically inferred value $(700 \mathrm{~m})$. The sedimentation rate at the location of the OD-3 core site is $0.6 \mathrm{~m} / \mathrm{kyr}$ for the period of 1.8-2.4 Myr, corresponding to the lower Tanaka Formation, whereas that in the Uemachi Upland is $0.5 \mathrm{~m} /$ kyr for the same period (Fig. 10c); the former is comparable with geologically inferred values, but the latter is a little faster than the geologically inferred values (Table 1 ). Consequently, there are discrepancies in the mean displacement rate, the basement depth, and the thickness of the upper sediment layers between the simulation results and the geological observations in the Uemachi Upland. To resolve these discrepancies, the displacement rate along the western fault needs to be enhanced by decreasing the dip angle of the fault at least partially and/ or by decreasing the friction coefficients. Accordingly, we evaluated gentler $\left(30^{\circ}\right)$ or curved western fault cases (Fig. 11). In the curved fault cases, the dip angle of the western fault is $40^{\circ}$ at the surface and gradually decreases with depth. The dip angle of the deeper part $(>7 \mathrm{~km}$ ) of the western fault is constant and is $20^{\circ}$ in the curved fault case and $15^{\circ}$ in the more curved fault case.

Figure 11a illustrates the results of the case with the gentler dip angle $\left(30^{\circ}\right)$ for the western fault (the gentler Uemachi case). The displacement rate along the western fault is much higher than that in the case with the dip angle of the western fault set to $40^{\circ}$, whereas the displacement rate along the eastern fault is lower than that in the case with the dip angle of the western fault set to $40^{\circ}$, implying that more deformation is partitioned to the western fault, decreasing the displacement rate along the eastern fault. Although the dip angle of the both faults is the same, the displacement rate along the western fault is lower than that along the eastern fault. It may result from the effects of viscous flow near the bottom of the lower basement layer; when the adjacent, parallel preexisting
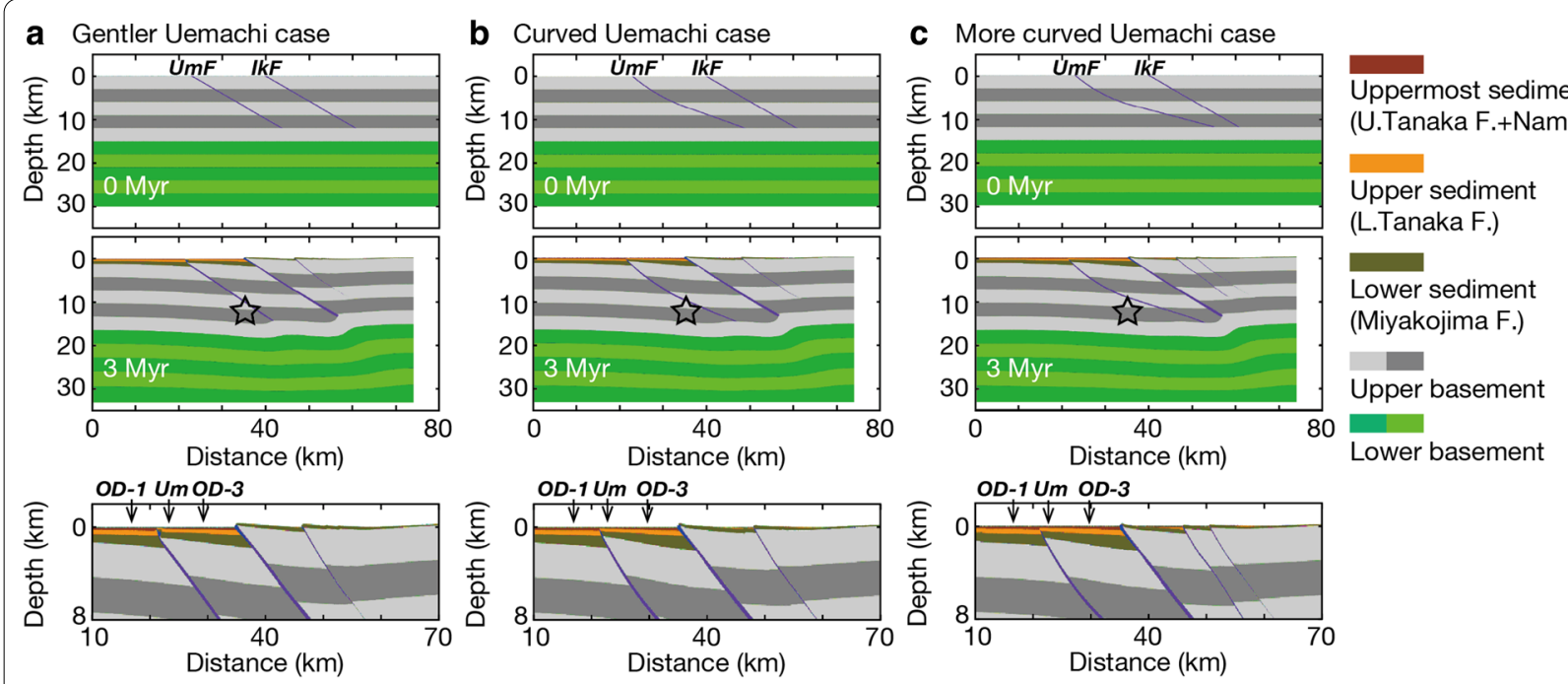

d Vertical displacement rate $(\mathrm{m} / \mathrm{kyr})$

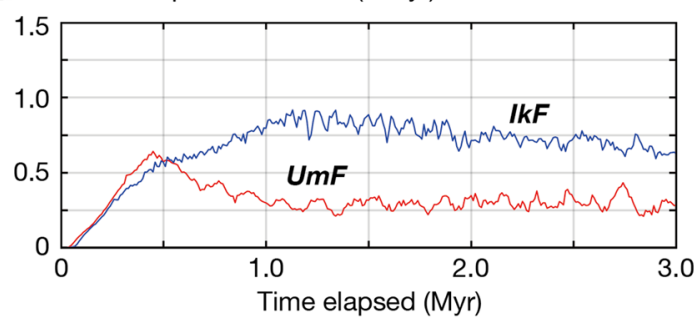

e Sedimentation rate $(\mathrm{m} / \mathrm{kyr})$

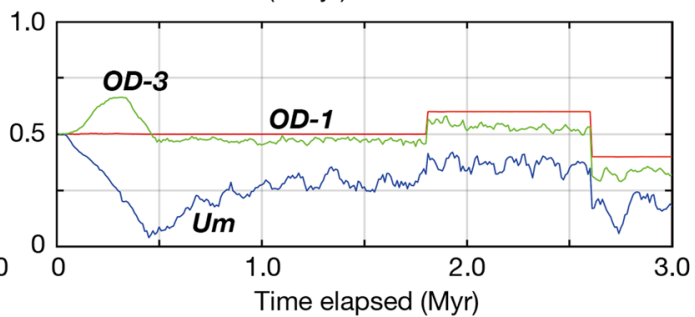

Fig. 11 Effect of changing the dip angle of the western fault (i.e., the Uemachi fault) on the development of the geologic structures. a-c The initial geometry (upper), final geometry (middle), and close-up of the final geometry (lower) of the linear fault case with a dip angle of $30^{\circ}$ (a), the curved fault case $(\mathbf{b})$, and the more curved fault case $(\mathbf{c})$. The preexisting faults and newly formed faults (markers with a cumulative strain larger than 1) are illustrated in dark blue. UmF and IkF represent the surface positions of the Uemachi and Ikoma faults, respectively. The hypocenter of the 2018 northern Osaka earthquake (Kato and Ueda 2019), located $12 \mathrm{~km}$ beneath the surface position $14 \mathrm{~km}$ east from the Uemachi fault, is indicated by a star in the panels showing the result at 3 Myr. OD-1, Um and OD-3 indicate the location of the OD-1, OD-9 and OD-3 core sites, respectively. $\mathbf{d}$ Time evolution of the vertical displacement rates along the western and eastern faults for the curved case. e Time evolution of the sedimentation rates in the Uemachi Upland (i.e., at the location of the OD-9 core site) and at the location of the OD-3 core site for the curved case. The imposed sedimentation rates at the location of the OD-1 core site are also shown 
faults are eastward dipping, the downward extension of the easternmost fault (i.e., the eastern fault in this case) develops as a lower crustal high-strained zone connecting to the basal viscous flow and then the strain localizes into the eastern fault (Additional file 1: Fig. S1). The eastern fault and its downward extension act as a bounding fault between the more deformed hanging wall block and less deformed footwall block. Based on a comparison with the geological observations, using the sum of squares of the difference between values of the model results and the geological observations for the thickness of the upper and uppermost sedimentary layers and basement depth, which is similar to the residual sum of squares, this gentler Uemachi case is more suitable; however, the difference between the geological observations and the simulation results is still large, especially the thickness of the uppermost sedimentary layer in the Uemachi Upland and the basement depth at the location of the OD-3 core site (Table 1).

The results of the curved fault cases (the curved and more curved Uemachi cases) are illustrated in Fig. 11b-e. Nearly horizontal sedimentary layers form in west Osaka, whereas an eastward thickening of the sedimentary layers is observed in east Osaka. The surface of the basement in east Osaka slopes to the east, whereas that in west Osaka is nearly horizontal. The degree of tilting toward the east of the east Osaka block in the curved western fault cases is larger than that in the non-curved cases. The thickness of the sediment layer in east Osaka in the more curved western fault case is larger than that in the less curved case (Table 1), due to a decrease in the displacement rate along the Uemachi fault in the more curved western fault case. Based on a comparison with the geological observations, the less curved case is the more suitable geometry for the present numerical model. In the curved fault case, the numerical results are consistent with the geological observations, even though the thickness of the uppermost sedimentary layer in the Uemachi Upland differs from the geological observations by $\sim 140 \mathrm{~m}$. This difference may be reduced by a higher vertical displacement rate along a fine-tuned, optimally curved western fault.

\section{Discussion}

\section{Comparison with the previously proposed fault geometry models for the Osaka Plain}

As previously mentioned, geometries of the deeper parts of the Uemachi and Ikoma faults have been proposed by Ishiyama (2003) and Sato et al. (2009). In this section, we evaluate their proposed Uemachi and Ikoma fault geometries.

Following Ishiyama (2003), we applied the dip angles of the western and eastern faults near the surface to be $40^{\circ}$ and $55^{\circ}$, respectively, corresponding to the Uemachi and Ikoma faults (Fig. 12a). The surface positions of the two faults were the same as in the cases with two preexisting fault zones. The eastern fault was linear, whereas
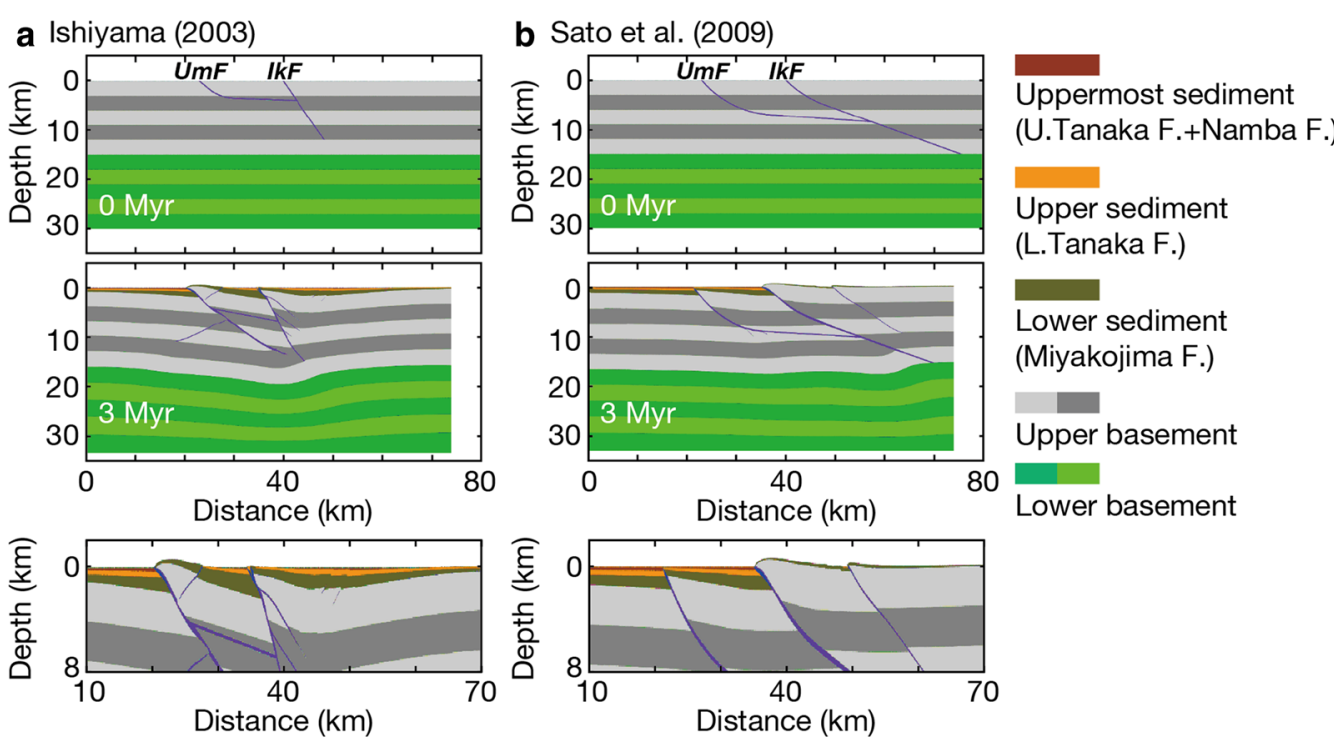

Fig. 12 Results of the numerical simulations for previously proposed fault geometries. a The initial geometry (upper), final geometry (middle), and close-up of the final geometry (lower) for the fault geometry of Ishiyama (2003) with a weakened friction coefficient $\mu_{w}$ of $\sim 0.3$ (weakened friction angle $\varphi_{w}=17^{\circ}$ ). b The initial geometry (upper), final geometry (middle), and close-up of the final geometry (lower) for the fault geometry of Sato et al. (2009) with $\mu_{w}=\sim 0.4\left(\varphi_{w}=22^{\circ}\right)$. The preexisting faults and newly formed faults (markers with a cumulative strain larger than 1) are illustrated in dark blue. UmF and IkF represent the surface positions of the Uemachi and Ikoma faults, respectively 
the western fault had a downward convex curving part at a depth of $\geq 1.5 \mathrm{~km}$, became nearly horizontal $\left(2^{\circ}\right)$ at a depth of $3.5 \mathrm{~km}$, and then converged to the eastern fault at a depth of $\sim 4 \mathrm{~km}$. Because a preexisting weak fault with a dip angle of $\sim 60^{\circ}$ is active when the weakened friction coefficient $\left(\mu_{w}\right)$ is less than $\sim 0.4$, we performed numerical simulations for this case with $\mu_{w}=0.3$. In this case, the eastern fault and the shallower part (dip angle of $40^{\circ}$ ) of the western fault are active, but displacement along the deeper $(>3.5 \mathrm{~km})$ and horizontal $\left(<2^{\circ}\right)$ parts of the western fault does not occur. A newly formed fault with a dip angle of $\sim 30^{\circ}-40^{\circ}$ propagates from the shallower and steeper parts of the western fault, and displacement related to the Uemachi fault occurs along this newly formed fault. This result implies that a thinskinned thrust converging to a low-angle detachment in the upper crust would not be active. The displacement along the eastern fault is significant, but a large-scale downward fold, i.e., synform, is formed in the area east to the eastern fault, leading to the development of a sedimentary basin.

According to Sato et al. (2009), the western fault has a near surface dip angle of $50^{\circ}$, transitions to gently dipping at a depth of $\sim 7 \mathrm{~km}$, and then converges to the eastern fault at a depth of $\sim 9 \mathrm{~km}$ (Fig. 12b) with a dip angle of $4^{\circ}$. The dip angle of the eastern fault near the surface was set to $45^{\circ}$, and the eastern fault transitioned to gently dipping at a depth of $5 \mathrm{~km}$. Below the converged depth, the dip angle of the eastern fault was set to $20^{\circ}$. The surface positions of the two faults were the same as in the cases with two preexisting fault zones. We performed numerical simulations for this case with $\mu_{w}=0.4$. The simulation results are similar to the curved Uemachi case (Figs. 11b and $12 \mathrm{~b}$ ), which correspond roughly to the geological observations (Table 1). The displacements along the lower $(>9 \mathrm{~km})$ and horizontal $\left(<4^{\circ}\right)$ parts of the Uemachi fault are not significant, and the newly formed highstrained zones with a dip angle of $\sim 30^{\circ}-40^{\circ}$ propagate from the upper bound of the lower and horizontal parts (Additional file 1: Fig. S2). Therefore, the geometry of the high-strained zones with high strain rate (i.e., active fault segments) in this model is similar to that of our curved Uemachi case, although the friction coefficient between them is different.

\section{Evaluation of the present fault geometry models for the Osaka Plain}

In the present model cases with two preexisting faults, the vertical displacement rate related to the western and eastern faults, i.e., Uemachi and Ikoma faults, increases to the maximum values at $\sim 0.5-1 \mathrm{Myr}$ and then becomes almost stable (Figs. 10b and 11d). If the onset of activity of the Ikoma fault is prior to that of the Uemachi fault, the displacement along the Ikoma fault would be much more than the results in this study. The geological evidence of the displacement of the Ikoma fault is recorded only in the Osaka Group after $3 \mathrm{Ma}$. The onset of fault activity may be earlier for the Ikoma fault than for the Uemachi fault, but we do not know exactly when the Ikoma fault zone was activated. Because Quaternary sediments are basically absent in the Ikoma Mountains, the Ikoma Mountains may have been separated from the marine waters at $3 \mathrm{Ma}$. However, because the elevation of the Ikoma Mountains at $3 \mathrm{Ma}$ is unknown, the elevation of the mountains was assumed to be $0 \mathrm{~m}$ at $3 \mathrm{Ma}(t=0 \mathrm{Myr})$ in this study. This assumption would have an impact on the thickness of the lower sedimentary layer (i.e., 3-1.2 Ma Miyakojima Formation). However, the thickness of the Miyakojima Formation beneath the Osaka Plain is not clear (Uchiyama et al. 2001), and we cannot evaluate the model results based on a comparison with the geological observations. The vertical displacement rate related to the Uemachi and Ikoma faults becomes stable after $\sim 0.5-1 \mathrm{Myr}$, corresponding to 2.5-2 Ma. Therefore, in this study, we evaluated the large-scale variation in the thickness of the upper and uppermost sedimentary layers, corresponding to the Tanaka and Namba formations, in the area in-between the Uemachi and Ikoma faults, and then the effect of the difference in onset of the activity between the Uemachi and Ikoma faults would be small.

The difference in the thickness of the uppermost sedimentary layer between the simulation results and the geological observations may also be due to the effect of the changing sedimentation rate for the uppermost sedimentary layer. In this study, we set the mean sedimentation rate at the OD- 1 core site to $0.4 \mathrm{~m} / \mathrm{kyr}$ from 2.6 Myr to 3.0 Myr, even though the sedimentation rate from $\sim 0.4 \mathrm{Ma}$ to $\sim 0.05 \mathrm{Ma}$ actually decreased from $0.5 \mathrm{~m} / \mathrm{kyr}$ to $0.2 \mathrm{~m} / \mathrm{kyr}$ (Fig. 4 ; Uchiyama et al. 2001). Furthermore, in the present simulation models, the subsidence rate in west Osaka decreases with distance from the western fault, even though, based on gravity and seismic reflection data (e.g., Nakagawa et al. 1996b; Iwabuchi 2000), the top of the basement deepens toward the west and the deepest part of the Osaka Bay is located $\sim 27 \mathrm{~km}$ from the Uemachi fault, where the NNE-SSW-trending Osaka-wan fault is located. The Osaka-wan fault is an ESE-side-down reverse fault, having a mean vertical displacement rate of $0.5-0.6 \mathrm{~m} / \mathrm{kyr}$ after $1 \mathrm{Ma}$ (Yokokura et al. 1998). If the subsidence rate at the OD-1 site related to the activity of the Osaka-wan fault is higher than that used in the present models, the sedimentation rate in east Osaka will be lower because the imposed rising rate of the sea level will be reduced. 
The subsidence rate at the OD-1 site also may be related to the large-scale folding in the Kinki region. It has been suggested that the large-scale folding developed in and around the Seto Inland Sea region during the Quaternary (e.g., Sugiyama 1992). If the half wavelength of the large-scale crustal folding would be shorter than $\sim 80 \mathrm{~km}$, the effect of the large-scale folding should be considered. To incorporate the effect of the large-scale crustal folding, we must perform the numerical simulation for a wide area. However, to perform the wide area simulation, we should introduce other preexisting active faults (e.g., Osaka-wan fault, Nara Basin eastern edge fault, and so on) into the model domain, but the geometry of these faults is not clear. Furthermore, although the large-scale folds develop in the Seto Inland Sea region, their eastern extension in the Kinki region is not clear (e.g., Sugiyama 1992). The present-day stress pattern in the Kinki region may be different from that in the Seto Inland Sea region (Terakawa and Matsu'ura 2010).

Based on the deep seismic reflection profile across the Kinki region, Sato et al. (2009) interpreted that horizontal mid-crustal reflectors near the bottom of seismogenic zone at 15 to $16 \mathrm{~km}$ in depth as a possible mid-crustal detachment. However, in the present numerical simulations of a two-dimensional visco-elasto-plastic body under a horizontal compressive stress field, the major faults, which are modeled as localized high strain zones, develop only above the frictional-viscous transition zone but their downward extensions form broad high strain zones, suggesting that the major faults are rooting at the bottom of the crust and mid-crustal horizontal shear zones are not developed (see Additional file 1: Figs. S1 and S2).

\section{Concluding remarks}

In this study, to examine the geometries of the active faults from the surface to the seismogenic zone, we analyze the development of the geological structures of sedimentary layers based on numerical simulations of a two-dimensional visco-elasto-plastic body under a horizontal compressive stress field, including preexisting high-strained weak zones (i.e., preexisting faults) and surface sedimentation processes, and evaluate the relationship between the observed geological structures of the Quaternary sediments (i.e., the Osaka Group) in the Osaka Plain and the model results.

Based on the results for the cases with or without a preexisting fault, when the friction coefficient of the faults is $\sim 0.5$, we found that (1) the localized highstrained zones (i.e., faults) develop from the surface to the frictional-viscous transition zone $(\sim 12 \mathrm{~km}$ depth); (2) the dip angles of the faults are $\sim 30^{\circ}-40^{\circ}$ near the surface, which are consistent with the theoretical dip angles of shear bands in compressional setting, but bend gently near the frictional-viscous transition depth; (3) the blocks between faults with the same dip direction tilt antithetically, whereas the blocks between faults with opposite dip directions rise or sink vertically; and (4) displacement along the preexisting fault with a dip angle of $30^{\circ}$ in the upper basement layer is much larger than that along the preexisting faults with lower and higher dip angles (i.e., $15^{\circ}, 45^{\circ}$, and $60^{\circ}$ ).

Based on the results for the cases with two preexisting faults, corresponding to the Uemachi and Ikoma faults in the Osaka Plain, we can conclude that, the dip angles of the Uemachi and Ikoma faults near the surface are $~ 30^{\circ}-$ $40^{\circ}$ and the Uemachi fault has a downward convex curve at the bottom of the seismogenic zone, but does not converge to the Ikoma fault. This implies that the downward extension of the Uemachi fault zone nearly coincides with the hypocenter of the 2018 northern Osaka earthquake. The dip angles of the active faults estimated in this study are lower than those estimated in the previous studies.

If the active fault has a low angle, the width of the fault plane is long, and thus the estimated seismic moment will be large. In the shallow part of the active faults with low dip angles, the fault plane is close to the ground surface and then peak ground acceleration will be higher. These factors will have an important effect on the prediction of ground motion caused by earthquakes that occur on the active faults. As described in this paper, the method based on the comparison between the geological observations and the simulation results of a two-dimensional visco-elasto-plastic body is useful to estimate the geometries of active faults from the surface to the seismogenic zone. It is crucial for seismic hazard assessments not only in urban areas but also in mountain areas.

\section{Abbreviations}

ATF: Arima-Takatsuki fault zone; GSJ: Geological Survey of Japan; IkF: Ikoma fault; MEXT: Ministry of Education, Culture, Sports, Science and Technology of Japan; NbF: Nara Basin eastern edge fault zone; OwF: Osaka-wan fault zone; PF: Preexisting fault; UmF: Uemachi fault.

\section{Supplementary Information}

The online version contains supplementary material available at https://doi. org/10.1186/s40623-021-01390-8.

Additional file 1: Fig. S1. Strain rate $\left(\dot{\varepsilon}_{\text {II }}\right)$ evolution within the model domain for the case of two preexisting fault zones with a dip angle of $30^{\circ}$ that is the same as Fig. 11 a. Fig. S2. Strain rate $\left(\dot{\varepsilon}_{\text {II }}\right)$ distribution within the model domain for the fault geometry of Sato et al. (2009) that is the same as Fig. 12b.

\section{Acknowledgements}

We thank TV Gerya for his providing the I2ELVIS code via the Cambridge University Press website (https://www.cambridge.org/9780521887540). This 
paper benefited from detailed reviews by two anonymous referees. M Furuya and TYamasaki are thanked for their editorial handling of the manuscript.

\section{Authors' contributions}

$\mathrm{HN}, \mathrm{TO}$, and Kl performed the numerical simulations and evaluated the model results. MM evaluated the geological features in the Osaka Plain to constrain the model results. HN and TO drafted mainly the manuscript, and all authors read and approved the final manuscript.

\section{Funding}

This study was supported by JSPS KAKENHI Grant Numbers 20K04087 and $18 \mathrm{H} 01297$.

\section{Availability of data and materials}

All data generated or analyzed during this study are available from the corresponding author on reasonable request.

\section{Declarations}

\section{Competing interests}

The authors declare that they have no competing interests.

\section{Consent for publication}

Not applicable.

\section{Author details}

1 Department of Geosciences, Osaka City University, Osaka 558-8585, Japan. ${ }^{2}$ Department of Physical Sciences, Osaka Prefecture University, Sakai 599-8531, Japan.

Received: 8 January 2021 Accepted: 1 March 2021

Published online: 09 April 2021

\section{References}

Allken V, Huismans RS, Thieulot C (2012) Factors controlling the mode of rift interaction in brittle-ductile coupled systems: A 3D numerical study. Geochem Geophys Geosyst 13:Q05010. https://doi.org/10.1029/2012G C004077

Allmendinger RW (1998) Inverse and forward numerical modeling of trishear fault-propagation folds. Tectonics 17:640-656. https://doi.org/10.1029/ 98TC01907

Carpenter BM, Saffer DM, Marone C (2015) Frictional properties of the active San Andreas Fault at SAFOD: implications for fault strength and slip behavior. J Geophys Res 120:5273-5289. https://doi.org/10.1002/2015J B011963

Director General for Disaster Management (2006) Evaluation of inundation possibility associated with crustal deformation due to earthquake in the Uemachi fault zone. http://www.bousai.go.jp/kaigirep/chuobou/senmon/tounankai_nankaijishin/pdf/2_kohyo.pdf. Accessed 10 Sept 2020

Döhmann MJEA, Brune S, Nardini L, Rybacki E, Dresen G (2019) Strain localization and weakening processes in viscously deforming rocks: numerical modeling based on laboratory torsion experiments. J Geophys Res: Solid Earth 124:1120-1137. https://doi.org/10.1029/2018JB016917

Gerya T (2010) Introduction to numerical dynamic modelling. Cambridge Univ Press, New York

Gerya TV, Yuen DA (2003) Rayleigh-Taylor instabilities from hydration and melting propel "cold plumes" at subduction zones. Earth Planet Sci Lett 212:47-62. https://doi.org/10.1016/S0012-821X(03)00265-6

Gerya TV, Yuen DA (2007) Robust characteristics method for modelling multiphase visco-elasto-plastic thermo-mechanical problems. Phys Earth Planet Int 163:83-105. https://doi.org/10.1016/j.pepi.2007.04.015

Gerya TV, Fossati D, Cantieni C, Seward D (2009) Dynamic effects of aseismic ridge subduction: numerical modelling. Eur J Mineral 21:649-661. https:// doi.org/10.1127/0935-1221/2009/0021-1931

Headquarters for Earthquake Research Promotion of MEXT (2001) Long-term evaluation of Ikoma fault zone. http://www.jishin.go.jp/main/chousa/ katsudansou_pdf/77_ikoma.pdf. Accessed 10 Sept 2020
Headquarters for Earthquake Research Promotion of MEXT (2004) Long-term evaluation of Uemachi fault zone. http://www.jishin.go.jp/main/chousa/ katsudansou_pdf/80_uemachi.pdf. Accessed 10 Sept 2020

Headquarters for Earthquake Research Promotion of MEXT (2005) Supplement of Report: Methods of evaluating active fault for fundamental survey and observation. http://www.jishin.go.jp/main/choukihyoka/05aug_hyoka shuhou/furoku.pdf. Accessed 10 Sept 2020

Hirth G, Teyssier C, Dunlap WJ (2001) An evaluation of quartzite flow laws based on comparisons between experimentally and naturally deformed rocks. Int J Earth Sci 90:77-87. https://doi.org/10.1007/s005310000152

Horike M, Takeuchi Y, Toriumi I, Fujita T, Yokota H, Noda T (1995) Seismic reflection survey of the boundary region between the Ikoma mountains and the Osaka basin. Zisin 48:37-49. https://doi.org/10.4294/zisin1948.48.1_

Huzita K (1968) Rokko movements and its appearance -Intersecting structural patterns of southwest Japan and Quaternary crustal movements. Quaternary Res 7:248-260. https://doi.org/10.4116/jaqua.7.248

Huzita K (1990) Manchidani Unconformity and Rokko movements -Middle Pleistocene fault-block movement and sea-level rise in Kinki. Japan Quaternary Res 29:337-349. https://doi.org/10.4116/jaqua.29.337

Huzita K, Kasama T (1982) Geology of the Osaka-Seinambu district, Quadrangle Series, scale 1:50,000. Geological Survey of Japan, Tsukuba

Ikari MJ, Marone C, Saffer DM (2011) On the relation between fault strength and frictional stability. Geology 39:83-86. https://doi.org/10.1130/ G31416.1

Ikebe N, Huzita K (1966) The Rokko movements, the Pliocene-Pleistocene crustal movements in Japan. Quaternaria 8:277-287

Ikebe N, Iwatsu J, Takenaka J (1970) Quaternary geology of Osaka with special reference to land subsidence. J Geosci Osaka City Univ 13:39-98

Ishiyama T (2003) Geometry and kinematics of the Uemachi and Ikoma fault zones beneath Metropolitan Osaka, central Japan. Ann Rep Active Fault Paleoearthquake Res 3:145-155

Itihara M (1993) Osaka Group. Sogensha Publishing, Osaka

Itihara M, Yoshikawa S, Kawabe T, Mitamura M (1984) On so-called "Shiba Unconformity" in the drainage area of the River Tsuda, Kishiwada City, Osaka-Magnetostratigraphy and fission track age of the Osaka Group. Earth Sci 38:1-16. https://doi.org/10.15080/agcjchikyukagaku.38.1_1

Itoh Y, Takemura K, Ishiyama T, Tanaka Y, Iwaki H (2000) Basin formation at a contractional bend of a large transcurrent fault: Plio-Pleistocene subsidence of the Kobe and northern Osaka Basin, Japan. Tectonophysics 321:327-341. https://doi.org/10.1016/S0040-1951(00)00072-X

Iwabuchi Y (2000) Active structures in Osaka Bay and Ise Bay. Quaternary Res (Daiyonki-Kenkyu) 39:303-314. https://doi.org/10.4116/jaqua.39.303

Iwasaki Y (2016) Fundamental mistake for estimation of the strong ground motion and displacements from Uemachi fault earthquake by the Central Disaster Management Council of the Cabinet Office, Government of Japan. Geoinformatics 27:66-69

Kansai Geo-informatics Council (1998) New Kansai-jiban. Kobe and Hanshin Regions, Kansai Geoinformatics Agency/Geo-Research Institute, Osaka

Kato A, Ueda T (2019) Source fault model of the $2018 M_{W} 5.6$ northern Osaka earthquake, Japan, inferred from the aftershock sequence. Earth Planets Space 71:11. https://doi.org/10.1186/s40623-019-0995-9

Kaus BJP (2010) Factors that control the angle of shear bands in geodynamic numerical models of brittle deformation. Tectonophysics 484:36-47. https://doi.org/10.1016/j.tecto.2009.08.042

Mannu U, Ueda K, Willett SD, Gerya TV, Strasser M (2016) Impact of sedimentation on evolution of accretionary wedges: Insights from high-resolution thermomechanical modeling. Tectonics 35:2828-2846. https://doi.org/ 10.1002/2016TC004239

Midorikawa S (1993) Semi-empirical estimation of peak ground acceleration from large earthquakes. Tectonophysics 218:287-295. https://doi.org/10. 1016/0040-1951(93)90275-O

Mitamura M, Matsuyama N, Nakagawa K, Yamamoto K, Suwa S (1994) Stratigraphy and subsurface structure of Holocene deposits around Uemachi Upland in the central Osaka Plain. J Geosci Osaka City Univ 37:183-212

Morrow CA, Moore DE, Lockner DA (2000) The effect of mineral bond strength and adsorbed water on fault gouge frictional strength. Geophys Res Lett 27:815-818. https://doi.org/10.1029/1999GL008401

Nakagawa K, Inoue N, Ryoki K (1996a) Basement structure of Osaka basin. Urban Earthquake Hazard Res Center Rep, 18:11-25 
Nakagawa K, Shiono K, Inoue N, Sano M (1996b) Geological characteristics and problems in and around Osaka Basin as a basis for assessment of seismic hazard. Soils Found 36(Supplement):15-28. https://doi.org/10.3208/ sandf.36.Special_15

Nakata T, Okada A, Suzuki Y, Watanabe M, Ikeda Y (1996a) 1:25,000-scale Active Fault Map in Urban Area, Osaka Tohoku-bu. Technical Materials of the Geographical Survey Institute, D.1-no. 333

Nakata T, Okada A, Suzuki Y, Watanabe M, Ikeda Y (1996b) 1:25,000-scale Active Fault Map in Urban Area, Osaka Tonan-bu. Technical Materials of the Geographical Survey Institute, D.1-no. 333

Okada A, Togo M (2000) Active Faults in the Kinki Area, Central Japan: Sheet Maps and Inventories. Univ Tokyo Press, Tokyo

Okada A, Uemura Y, Togo M, Nakata T, Watanabe M (1996) 1:25,000-scale Active Fault Map in Urban Area, Kyoto Seinan-bu. Technical Materials of the Geographical Survey Institute, D.1-no. 333

Okubo Y, Uchida Y, Taniguchi M, Miyakoshi A, Safanda J (2005) Statistical analysis for thermal data in the Japanese Islands. Phys Earth Planet Inter 152:277-291. https://doi.org/10.1016/j.pepi.2005.04.013

Osaka Prefecture (2004) Survey for the underground structure in the Osaka Plain. Report for basic earthquake-related survey grant FY2003, Osaka

Ruh JB, Gerya T, Burg JP (2014) 3D effects of strain vs. velocity weakening on deformation patterns in accretionary wedges. Tectonophysics 615-616:121-141. https://doi.org/10.1016/j.tecto.2014.01.003

Rybacki E, Dresen G (2004) Deformation mechanism maps for feldspar rocks. Tectonophysics 382:173-187. https://doi.org/10.1016/j.tecto.2004.01.006

Sato H, Ito K, Abe S, Kato N, Iwasaki T, Hirata N, Ikawa T, Kawanaka T (2009) Deep seismic reflection profiling across active reverse faults in the Kinki Triangle, central Japan. Tectonophysics 472:86-94. https://doi.org/10. 1016/j.tecto.2008.06.014

Shimokawa K, Kariya Y, Miyachi Y, Sangawa A (1997) Survey for the activity of the Ikoma fault system. GSJ Open-file Rep, 303:37-49

Sugiyama Y (1992) Neotectonics of the forearc and the Setouchi Province in southwest Japan. Mem Geol Soc Japan, 40:219-233

Sugiyama Y (1997) Seismic reflection survey of the Uemachi fault system. GSJ Open-file Rep, 303:105-113

Sugiyama Y, Sangawa A (1996) Seismic reflection survey of the southward extension of the Uemachi fault in the Yamato River, southern Osaka Plain. GSJ Interim Rep, no. EQ/96/1, p.57-62

Sugiyama Y, Shimokawa K, Awata Y, Satake K, Mizuno K, Yoshioka T, Komatsubara T, Nanayama F, Kariya Y, Azuma T, Fusejima Y, Tsukuda E, Sangawa A, Sugai T (1999) Summarized survey result and earthquake potential of major active faults in the Kinki Triangle, central Japan. GSJ Interim Rep, no. EQ/99/3, p.285-309

Sugiyama Y, Nanayama F, Kitada N, Yokota H (2001) S-wave seismic reflection survey of the Uemachi fault in Osaka City. Ann Rep Active Fault Paleoearthquake Res, 1:143-151

Sugiyama Y, Nanayama F, Miura K, Yoshikawa T, Yokota H, Suehiro M, Furutani M, Tochimoto Y, Hirose K, Yokoyama Y, Kitada N, Takemura K (2003) Complementary study of the Uemachi fault system in the Osaka Basin (2) -Evaluation of the fault activity based on supplementary boring and re-interpretation of S-wave seismic reflection data-. Ann Rep Active Fault Paleoearthquake Res, 3:117-144

Suzuki K (2016) Sedimentation rate and sedimentary process of the lower half of the Lower part of the Osaka Group, central Japan. J Sediment Soc Japan 75:25-34

Takahashi M, Mizoguchi K, Kitamura K, Masuda K (2007) Effects of clay content on the frictional strength and fluid transport property of faults. J Geophys Res 112:B08206. https://doi.org/10.1029/2006JB004678

Terakawa T, Matsu'ura M (2010) The 3-D tectonic stress fields in and around Japan inverted from centroid moment tensor data of seismic events. Tectonics 29:TC6008. https://doi.org/10.1029/2009TC002626

Tsukahara H, Kobayashi Y (1991) Crustal stress in the central and western parts of Honshu, Japan. Zisin 44:221-231. https://doi.org/10.4294/zisin1948. 44.3_221

Tsutsumi H, Sato K, Yamaji A (2012) Stability of the regional stress field in central Japan during the late Quaternary inferred from the stress inversion of the active fault data. Geophys Res Lett 39:L23303. https://doi.org/10. 1029/2012GL054094

Uchiyama M, Mitamura M, Yoshikawa S (2001) Displacement rate of the Uemachi Fault and basement block movements of the Osaka Plain, Southwest Japan. J Geol Soc Japan 107:228-236. https://doi.org/10.5575/ geosoc.107.228

Vermeer PA (1990) The orientation of shear bands in biaxial tests. Géotechnique 40:223-236. https://doi.org/10.1680/geot.1990.40.2.223

Vermilye JM, Scholz CH (1998) The process zone: a microstructural view of fault growth. J Geophys Res 103:12223-12237. https://doi.org/10.1029/98JB0 0957

Wesnousky SG, Scholz CH, Shimazaki K (1982) Deformation of an island arc: Rates of moment release and crustal shortening in intraplate Japan determined from seismicity and Quaternary fault data. J Geophys Res 87:6829-6852. https://doi.org/10.1029/JB087iB08p06829

Yokokura T, Kano N, Yamaguchi K, Miyazaki T, Ikawa T, Ohta Y, Kawanaka T, Abe S (1998) Seismic profiling of deep geological structure in the Osaka Bay area. Bull Geol Surv Japan 49:571-590

Yoshikawa S, Mitamura M (1999) Quaternary stratigraphy of the Osaka Plain, central Japan and its correlation with oxygen isotope record from deep sea cores. J Geol Soc Japan 105:332-340. https://doi.org/10.5575/geosoc. 105.332

Yoshikawa S, Machida Y, Teramoto M, Yokota H, Nagao H, Kagiwara M (1987) Reflection seismic survey in Osaka City. Proc 77th SEGJ Conf, p.114-117

Yoshikawa S, Mizuno K, Katoh S, Satoguchi Y, Miyakawa C, Kinugasa Y, Mitamura M, Nakagawa K (2000) Stratigraphy and correlation of the Plio-Pleistocene volcanic ash layers from a 1,700 m core taken from Higashinada, Kobe City, southwestern Japan. Quaternary Res (DaiyonkiKenkyu) 39:505-520. https://doi.org/10.4116/jaqua.39.505

\section{Publisher's Note}

Springer Nature remains neutral with regard to jurisdictional claims in published maps and institutional affiliations.

\section{Submit your manuscript to a SpringerOpen ${ }^{\circ}$ journal and benefit from:}

- Convenient online submission

- Rigorous peer review

- Open access: articles freely available online

- High visibility within the field

- Retaining the copyright to your article

Submit your next manuscript at springeropen.com 